\title{
Sovereign Default, Exit and Contagion in a Monetary Union*
}

\author{
Sylvester C.W. Eijffinger, Michał L. Kobielarz and Burak R. Uras ${ }^{\dagger}$
}

February 23, 2018

\begin{abstract}
The euro area sovereign debt crisis is characterized by a simultaneous surge in the cost of borrowing for peripheral EMU countries following the Greek debt-trouble in 2008. We develop a model with optimal default and monetary-union exit decisions of a small open economy. Our model can account for the behavior of sovereign bond spreads in the eurozone with the arrival of the news of Greece potentially exiting the euro in the near future. In our theoretical framework, belonging to the monetary-union entails a strong exchange rate peg, which can be abandoned only if the country exits the union. Exit is costly and the cost of exit remains unknown until the first country leaves the union. The theoretical mechanism we explore reveals that while a high expected exitcost could improve the credibility of a monetary union, uncertainty governing exit-cost realizations could make the monetary-union members prone to surges in interest rates when rumors of a member state exiting arise. We solve the model numerically and quantify that a Grexit-rumors type of shock can triple the default likelihood of an a-priori financially healthy member state. Our framework thus provides a novel and quantitatively important explanation for the eurozone crisis.
\end{abstract}

Keywords: contagion, monetary union, sovereign debt crisis, exit. JEL Classification Numbers: F33, F34, F36, F41.

${ }^{*}$ For their suggestions and comments we would like to thank the editor, three anonymous reviewers, Anil Ari, Giancarlo Corsetti, Wouter den Haan, Michael Ehrmann, Andrea Ferrero, Pieter Gautier, Tommaso Monacelli, Louis Raes, Ctirad Slavik, Gonzague Vannoorenberghe, Harrie Verbon, Martin Wolf, Jean-Pierre Zigrand and the seminar participants at the ECB, Goethe University Frankfurt, Tilburg University, the EBC Junior Fellow Workshop, the SMYE in Lisbon, the RES Junior Conference and the ENTER Jamboree in Madrid for useful comments and discussions.

${ }^{\dagger}$ Kobielarz: CentER, Tilburg University. E-mail: michal.kobielarz@gmail.com. Eijffinger: Tilburg University and CEPR. Uras: Tilburg University. 


\section{Introduction}

We develop a model of sovereign debt and default and argue that ex-ante unknown monetaryunion exit costs can generate the contagion of a sovereign debt-crisis from a troubled member state (such as Greece) to healthy members of a monetary union (such as Portugal). Our study is motivated with the stylized experience of the southern euro area countries following the Greek debt trouble and the emergence of the rumors concerning the potential of Greece leaving the eurozone (Grexit). The sovereign debt crisis in the euro area is characterized by a simultaneous surge in the cost of borrowing for Southern European governments after 2008. As we document in Figure 1, at the dawn of the crisis in late 2008 the spread on Greek long-term government bonds (relative to the risk-free German bonds) rose from 50 basis points (bps) to 200 bps within a couple of months, and further increased to 1000bps by 2012. Shortly after the outbreak of the Greek debt trouble, the sovereign-bond spreads started to rise in Portugal, Italy and Spain as well. Many argue that this rise in interest rates in Southern Europe was the result of a contagion from Greece. ${ }^{1}$ Our dynamic model incorporates a microfounded theory building upon a union-exit cost uncertainty to account for such contagion.

We model widely-accepted characteristics of a monetary-union membership of a small open economy in a dynamic general equilibrium framework. Having committed to an extreme currency-peg through the monetary union membership limits a country's control over its monetary policy and exchange rate, constraining the set of policy instruments available to respond to aggregate shocks. Abandoning a monetary union could especially be attractive if exchange rate misalignments are causing high unemployment rates, as observed in some of the peripheral members of the European Economic and Monetary Union (EMU) since 2009. Despite the high output and unemployment costs suffered during the recent crisis though, we have not observed any departures yet from the EMU. The absence of an exit realization from the EMU could be the result of a high expected cost associated with departing the union. $^{2}$

In our model, we assume that a member state could regain control over its exchange rate policy by leaving the monetary union through incurring a cost of exit. We also assume that this exit cost could be high or low but most importantly the level of it is ex ante unknown

\footnotetext{
${ }^{1}$ See e.g. Constâncio (2012), Mink and de Haan (2013), Brutti and Sauré (2015) or Favero (2013).

${ }^{2}$ This might be the direct short-term cost in the form of output loss, or a financial turmoil and the operational cost of introducing a new currency, or the long-term cost of foregone international trade facilitated by the pegged currency.
} 
to the country of our interest - as well as to all other members of the union. There are two ways for the country to uncover the union-exit cost: (i) its government can execute a union-exit itself, and upon completion of this exit, together with the rest of the member states the county learns how costly it is to exit. (ii) It can wait for another member state to exit, such as Greece, and learn from that other member-state's experience how high the cost of union-exit is going to be.

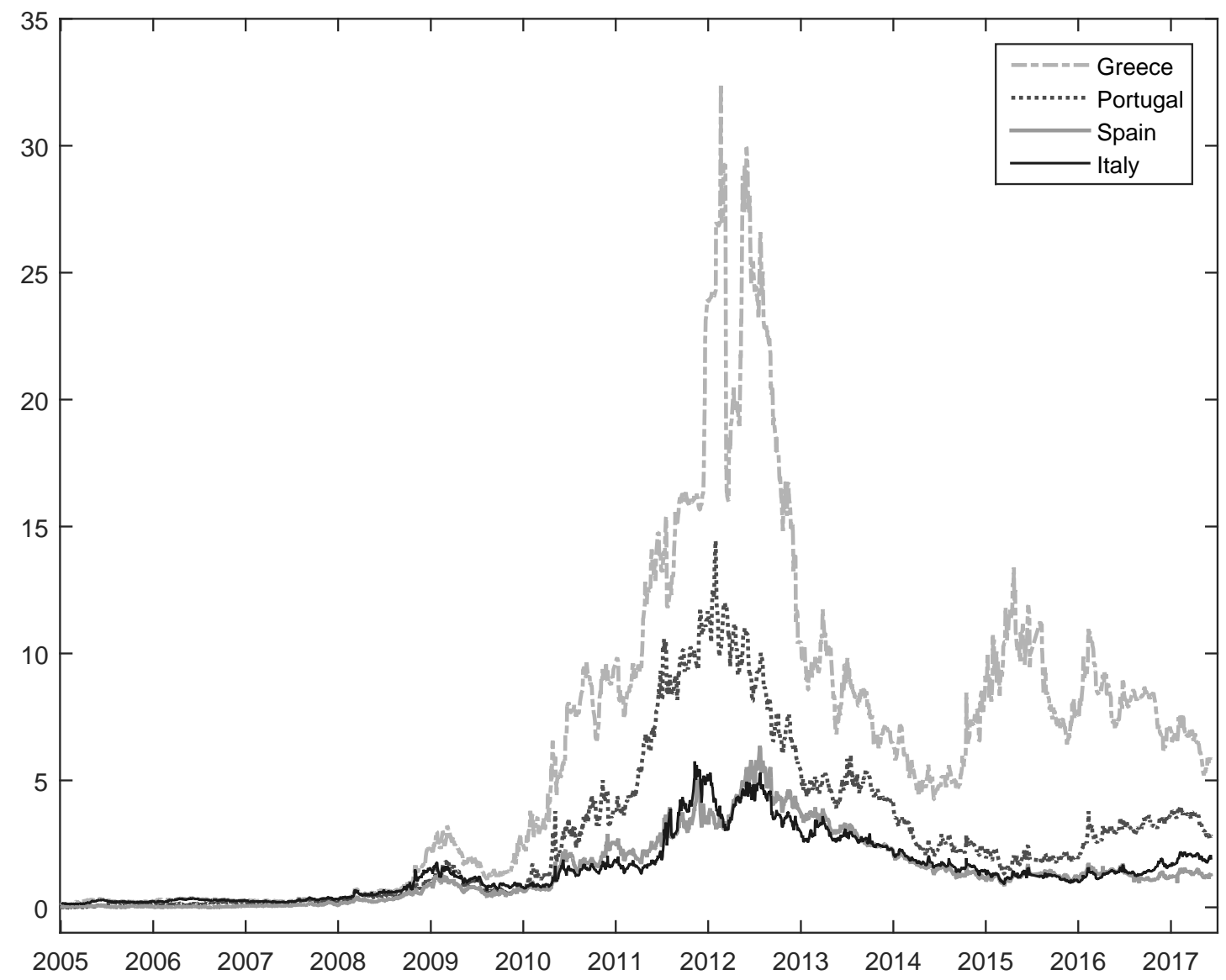

Figure 1: Spreads on government bonds of GIPS (relative to German bonds). Daily data on long-term (10-year) yields, obtained from Eurostat.

Because of the exit cost uncertainty, the first country exiting the union provides highly valuable information to all other union members. If it turns out that the first exit is a (relative) success, i.e. the exit cost is low, then more countries could follow the path of the first country exiting. In order to replicate the events of the eurozone crisis, during which the Greek debt-trouble spilled over to other EMU countries, we model an exit-rumors shock. In particular, in our quantitative experiments the monetary union gets hit by the exit rumors 
of a member state, which implies that the uncertainty governing the cost of exiting might resolve over a short period of time. The arrival of exit rumors associated with one memberstate (e.g. Greece) impacts the intertemporal debt market interactions of another member state with healthy enough fundamentals (such as Portugal), causing contagion in the form of rising sovereign interest rates also for this country.

The novel qualitative mechanism that we uncover works in the following way: when rumors about Greece exiting emerge, this generates a positive probability that the costuncertainty will be resolved soon, with Greece leaving the union. If it turns out that the exit cost is low, soon after Greece's departure Portugal might also consider to leave the union and devalue its newly instated currency - even with sufficiently strong initial fundamentals that prevented Portugal from exiting under the expected (and uncertain) cost of exit stateof-nature. ${ }^{3}$ Furthermore, if Portugal would re-denominate and convert its debt into the new currency after its union-exit, then because of the devalued new currency the union-exit also implies a partial default. Therefore, as a result of the convertibility-risk, rational external lenders price the consequences of a potential upcoming exit - and in particular its low-cost realization - and raise interest rates for initially untroubled member states, such as Portugal, following a Grexit-type rumors shock.

The default-premium charged on sovereign borrowing of Portugal would not be so disastrous, if Portugal could easily devalue and relieve the burden of debt. However, until the first exit is completed by Greece, Portugal suffers the cost of a potentially low exit-cost realization without enjoying any of its benefits. In other words, the Portuguese government has to pay a default premium on its bonds resulting from the potential revelation of a low exit-cost in the near future. At the same time though, it still faces the uncertainty about the union-exit cost, such that at an actual exit decision the government has to take the expected union-exit cost as given, under which Portugal might not find it optimal to execute an exit on its own, as observed in reality.

Finally, if a full-fledged default is also available (in the tradition of Eaton and Gersovitz (1981)), this reinforces the rise in interest rates, because high interest rates without the ability to devalue - yet - only worsen the financial and economic conditions for a country such as Portugal, potentially leading to a full-fledged default.

We introduce the above mechanism into a model of sovereign debt and default that explicitly incorporates a monetary-union exit decision for a small open economy's government.

\footnotetext{
${ }^{3}$ We would like to note that the perceived probability for Portugal to leave the union prior to the Grexit rumors was close to zero, as it was also evident in low interest rates charged by external lenders on Portuguese sovereign bonds before 2009 .
} 
Hereafter we will call the small open economy of our interest as the SOE. In our model default on sovereign debt and exit from the monetary union are two separate but interrelated decisions. A country may default and refuse to pay its external debt, or exit the union, devalue its currency and regain its international competitiveness, or both exit and default simultaneously. Union-exit, through a follow-up currency re-denomination, allows also for a de facto partial default.

We model the punishment for (outright) default as the exclusion from financial markets, accompanied by an output loss. The cost of exiting the monetary union is modeled as a onetime fixed cost, an assumption typical for the literature on currency crises (such as Obstfeld (1994, 1996)). Different from the currency crises literature though we assume that the cost of departure is a priori unknown. Agents form beliefs about the value of the cost of exiting, and the actual value becomes known to all agents only once one of the members completes an exit from the union. ${ }^{4}$

We enrich an Eaton and Gersovitz (1981) type of sovereign default model with our novel monetary union dynamics from the perspective of the SOE. The small open economy that we investigate resembles the key features of Schmitt-Grohé and Uribe (2016) and Na et al. (2018): specifically, (i) the SOE's tradable output is subject to aggregate shocks, (ii) during economic downturns - driven by tradable output shocks - downward rigidity in nominal wages generates involuntary unemployment and a motive for currency devaluation; and, (iii) the government can optimally default on its external debt in order to maximize the aggregate welfare. Default leads to the exclusion of the country from international financial markets and a contraction in tradable output in the future due to financial market exclusion and dead-weight losses.

Utilizing this framework, we investigate the macroeconomic dynamics generated by a news-driven shock associated with the emergence of a member state seeking an opportunity to exit the monetary union, which we interpret as the arrival of the news concerning Grexit rumors. Prior to the rumors shock, the SOE's government takes the expected cost of exit as unknown, forms expectations about it and undertakes exit and default decisions based on that. After exit-rumors the SOE-government undertakes its decisions with the expectation that in the near future the cost of exit could be revealed to all member states. More importantly, also international lenders take this potential short-run information revelation

\footnotetext{
${ }^{4}$ Instead of assuming that the cost is equal for all countries, one could assume that costs are correlated and the first exit provides partial information about the value of the exit-cost of the remaining countries. This alternative assumption would not change the qualitative implications of the model, but it would complicate the exposition and solution of the model substantially.
} 
into account and price the bonds of the SOE accordingly. Depending on the initial beliefs about the cost distribution, we show that the rumors shock generates a mechanism capable of worsening the financial conditions for a country with initially good standing, as in some peripheral EMU countries, and push the country into a debt crisis and even to default.

We solve this small open economy model numerically and show that for a relatively moderate expected cost of monetary-union exit, exit-rumors cause rising borrowing spreads and increase the likelihood of default for an initially healthy SOE. This qualitative property turns out to have quantitatively significant implications as well. Specifically, the rumors shock triples the periodic default likelihood of an a-priori healthy SOE, while it raises the periodic default probability by fourfold if the SOE had been experiencing a recession before the exit-rumors shock. The qualitative as well as quantitative properties of our framework are present in a variety of alternative cost specifications that we explore.

The key policy implication from our analysis is that the absence of an explicit exit-clause from a monetary union might be useful to improve the union's credibility, but it is also a source of financial instability and contagion that policy makers might need to pay attention to.

Related literature. We contribute to three strands of literature. Our first contribution is to the large literature on aggregate consequences of currency pegs. In this line of research our work is most related to two recent studies: Na et al. (2018) and Schmitt-Grohé and Uribe (2016). These two papers develop dynamic small open economy models to investigate the welfare cost of currency pegs borne by nominal rigidities in equilibrium wages. On the one hand, Schmitt-Grohé and Uribe (2016) concentrate on the interaction between capital mobility and currency pegs and show that this interaction generates inefficiently high borrowing in international capital markets during booms, which leads to high unemployment during contractions that is driven by rigid wages. The key conclusion from their set-up thus turns out to be the emergence of capital mobility restrictions as an optimal policy instrument in curbing the behavior of nominal wages over the business cycle. On the other hand, Na et al. (2018) study the interactions between default and currency devaluation and illustrate that under rigid wages and fixed exchange rates optimal default takes place when involuntary unemployment is high. Our paper develops a Schmitt-Grohé and Uribe (2016) style small open economy model as well, but differently we investigate the monetary-union dynamics generated by rigid nominal wages.

The second strand of research that we relate to is the literature on endogenous default in the context of sovereign debt markets a la Eaton and Gersovitz (1981). Recent stud- 
ies that investigated the theoretical features of sovereign default are Aguiar and Gopinath (2006), Arellano (2008), Yue (2010), Chatterjee and Eyigungor (2012), Arellano and Ramanarayanan (2012) and Mendoza and Yue (2012). ${ }^{5}$ In this literature attention to the contagion of sovereign default risk has been limited. Two exceptions are the studies by Lizarazo (2013) and Park (2013), both of which explore the role of investors' attitudes towards charging high risk-premia in sovereign debt markets during times of default and forcing initially untroubled countries into a financial crisis. We contribute to this literature in two ways. First of all, we study a small open economy model in a monetary union and incorporate not only the optimal default decision of the government, but also the optimal union-exit decision. Moreover, we uncover and study a novel theoretical mechanism that generates sovereign debt contagion within a monetary union. The mechanism relies on the potential of information revelation, in the case when the cost of exiting the union is unknown. The model establishes a link between default and exit decisions and highlights the strong interactions between countries within a monetary union during times of a debt crisis.

Also important for the literature on sovereign debt and default, Durdu et al. (2013) develop a dynamic small open economy model of sovereign debt \& default with (noisy) news shocks concerning the next period's TFP realization. This model structure provides the foundation for a theoretical mechanism, through which negative news about next period's TFP raises the default likelihood in the next period and causes a rise in sovereign interest in the current period. Our theoretical model also embeds a similar transmission mechanism. However, different from the set-up of Durdu et al. (2013) we model the monetary-union exit and sovereign default decisions jointly for the government of a small open economy (SOE), using which we then explore the consequences of potential upcoming exit news in the monetary union on the sovereign borrowing costs (and default) for SOE. In this respect, also different from the framework of Durdu et al. (2013) in our set-up it's not negative news per se, but the likelihood of an upcoming information revelation that causes a financial contagion to an initially healthy member of a monetary union.

Finally, and most importantly we contribute to the literature which explores contagion and the dynamics of sovereign bond spreads during the European sovereign debt crisis. Recent empirical studies discuss the puzzling behavior of spreads in the euro-area sovereign bond markets. Bernoth et al. (2012), Aizenman et al. (2013), Beirne and Fratzscher (2013) and Ghosh et al. (2013) using either yield spreads or CDS spreads document that sovereign

\footnotetext{
${ }^{5}$ Aguiar and Amador (2014) provide an excellent overview of the recent literature on sovereign debt and default.
} 
interest rates were mostly insensitive to fiscal variables prior to the crisis and that this changed drastically during the crisis. Moreover, Mink and de Haan (2013), Ludwig (2014), Kohonen (2014), De Santis (2014), Brutti and Sauré (2015) and Favero (2013) find empirical evidence for contagion in sovereign debt markets within the EMU. ${ }^{6}$

Our paper develops the first theoretical model to analyze contagion within the eurozone through the channel of information revelation. ${ }^{7}$ In this respect, our work provides an interpretation for the large body of empirical findings on contagion of sovereign debt crisis in EMU. Our model is also able to explain the findings of Ang and Longstaff (2013) that there is more systemic risk in the eurozone compared to the US. In our framework the systemic risk originates from the shared uncertainty about the union-exit cost and the possibility of an information revelation that is common to all members of the EMU. For the case of the US this systemic channel cannot be operational, because the departure of any individual state from the federation is an extremely unlikely event.

\section{Uncertain Euro-Exit Cost and Domestic-Law Bonds}

There are two key features of our model that are important to generate the contagion mechanism. The first one is the uncertainty governing the ex-post revelation of monetary-union exit cost and the other one is the domestic-law bonds which allow debt re-denomination in the case of a domestic currency switch following a monetary-union exit. Both of these features are prevalent characteristics of the EMU.

In the institutional set-up of the EMU there is no explicit legal procedure for abandoning the monetary union. Therefore, until a first-time exit is observed, the member states will naturally not know how painful the process is going to be. In order to highlight an important detail to this end, even the exit protocol for an upcoming potential Grexit that was drawn by teams of Troika after the Greek debt crisis in 2012, had been discussed in absolute secrecy so that premature news \& plans would not leak.

The discussions by experts and policy makers following the Greek debt crisis had also proven the existence of a distribution of heterogeneous beliefs regarding the EMU-exit costs and also the belief that the cost of exiting euro is going to be learned by experience. One

\footnotetext{
${ }^{6}$ Beetsma et al. (2013) find also spill-over effects of "news" across troubled countries in the EMU during the crisis, but do not label those as contagion.

${ }^{7}$ Other theoretical models exploring the dynamics of the eurozone crisis include i.a. Aguiar et al. (2015), Corsetti et al. (2014), Corsetti and Dedola (2016), and Broner et al. (2014). These studies do not concentrate on contagion, with the exception of Bolton and Jeanne (2011) who explore contagion through a common lender channel. Alvarez and Dixit (2014) consider the potential of a break-up of the euro-area.
} 
of the biggest legal and institutional issues, that an exit might trigger, is the uncertainty of whether a country exiting the euro-area would be allowed to remain a member of the EU. The issue arises because the Maastricht Treaty requires all members of the EU to adopt the euro and join the eurozone. ${ }^{8}$ The treaty also specifies that the conversion of national currencies is irrevocable and the adoption of the euro irreversible. In a legal analysis of the issue of EU membership after a euro-exit, Athanassiou (2009) concludes that "a member state's exit from EMU, without a parallel withdrawal from the EU, would be legally inconceivable."

If an EMU exit implied also an EU exit, the whole process would become long and complicated, as it can be currently observed in the example of the UK. The fact that we do not know the legal status of "an EU member exiting the EMU" adds a very significant component to the uncertainty governing the union-exit cost.

On the high-cost expectations side, it had been highlighted that the short-term effects of Grexit would be so disruptive that it could lead to a civil unrest and cause a very significant contraction in consumption and wealth over a long horizon. On the low-cost side, proponents had been arguing that re-introducing drachma would be easy enough such that in the short-run exports and tourism can boost quickly to overcome the cost of abandoning the euro - allowing Greece to recover fast. To give a particular example from this end, in a column on May 2015, Paul Krugman stated the following:

"[T]he bigger question is what happens a year or two after Grexit, where the real risk to the euro is not that Greece will fail but that it will succeed." (New York Times. May 25, 2015)

Basically, a successful Grexit in the near future could trigger a domino effect of other successful EMU-exit experiences. Moreover, if Grexit would turn out to be a success, the expertise developed in Greece could easily be hired in other EMU countries, which might be interested in an easy-way-out from the eurozone as well.

The realistic existence of an exit-cost uncertainty and in particular the possibility of further successful departures in the near future following a low-cost (successful) realization of Grexit are what we formalize and study in this paper.

Another important aspect of our theoretical set-up is the association of a monetary-union exit with an endogenous currency devaluation and debt re-denomination. This feature of the model is highly prevalent for the context of the EMU as well. Specifically, as documented

\footnotetext{
${ }^{8}$ The only two exceptions are the UK and Denmark, who have negotiated opt-out clauses. The remaining countries are required to join, even though a formal deadline has not been set.
} 
by Schumacher et al. (2015) between 2003-2014 on average 90\% of the sovereign bonds originated in Portugal and in Spain and 99\% of sovereign bonds issued in Italy were issued under the domestic law. Domestic law bonds allow a sovereign to change the denomination of its external debt if the domestic currency of the country would change.

The existence of this option for a sovereign government implies for external lenders that the value of outstanding sovereign debt could contract after a currency transition, such as abandoning the euro. In particular for the eurozone countries, because of the high degree of exchange rate misalignments, the main rationale for abandoning the monetary union is the possibility to introduce a new currency and devalue. In this respect, the risk of re-denomination is not only a theoretical possibility in EMU. This convertibility-risk has been highlighted even by the President of the European Central Bank, Mario Draghi, during the eurozone debt crisis:

"Then there's another dimension to this that has to do with the premia that are being charged on sovereign states' borrowings. These premia have to do, as I said, with default, with liquidity, but they also have to do more and more with convertibility, with the risk of convertibility." ～(London, July 26, 2012, source: ECB (2012))

The words of Mario Draghi are empirically confirmed by De Santis (2015), who proposes to measure the convertibility risk as the spread between euro- and dollar-denominated sovereign bonds. Furthermore, to control for the differences in the liquidity premia in those two markets, they take the difference between this measure for a risky country and a safe country, e.g. the difference between the Spanish and the German spreads. He documents the existence of a convertibility risk premium for Spain, Italy and France during the period of 2011-2013. This suggests that in this time period markets were taking into account the risk of an EMU exit and a consequent re-denomination of sovereign bonds in those countries. Using an alternative approach, Kriwoluzky et al. (2015) estimate a DSGE model with exogenous exit expectations for Greece and find a significant contribution of these expectations to Greek risk premia and debt dynamics. Their results imply that exit expectations might drive a country into a debt crisis, which is consistent with the mechanism that we present in this paper.

Thus, the legal framework in Europe permits countries to re-denominate their debt after a monetary-union exit and anecdotal and empirical evidence points that this risk had been priced in by investors during the eurozone debt crisis - supporting one of the key features 
making up the backbone of our framework.

\section{Model}

We investigate the dynamic behavior of a small open economy, that we call the SOE, in a monetary union. The model builds upon the structure developed by Na et al. (2018) which is suitable to investigate the interactions between currency devaluation and sovereign-debt default in the tradition of Eaton and Gersovitz (1981). We enrich the framework of Na et al. (2018) by incorporating a monetary-union exit decision for the SOE. Monetary union members share a common currency, whose nominal exchange rate is fixed at an exogenously specified policy-rate. A member state, such as the SOE, can exit the union in any timeperiod and adopt its own domestic currency. If adopted, the country's own currency allows the government of the SOE to choose its own devaluation policy. As in Na et al. (2018) and Schmitt-Grohé and Uribe (2016) devaluation is desirable during times of an economic downturn because of the presence of a downward rigidity in nominal wages. Importantly, in our framework devaluation also reduces the burden of debt issued under the domestic law, as the country is allowed to convert the debt from the currency of the union into its own domestic currency upon monetary-union exit.

A key feature of the model is the costly exit from the monetary union. Specifically, in order to exit the monetary union and switch to its own domestic currency, the SOE has to incur a one-time cost. This cost is similar to the cost of abandoning an exchange rate peg, as traditionally assumed in the currency crises literature. As a crucial difference from the past literature, the level of the union-exit cost is uncertain and is revealed only when a member state completes an exit from the union. Given a set of initial conditions - which resemble the situation of the EMU at the on-set of the Greek sovereign-debt crisis and the emergence of Grexit rumors, we will show that the exit-cost uncertainty is capable of generating a mechanism for contagion of a sovereign debt crisis in the monetary union. Before we move on describing the key mechanism of the model, at first we present the decision programs of households, firms and the government. ${ }^{9}$

\footnotetext{
${ }^{9}$ The definition of the recursive equilibrium and the timing of the model can be found in Appendix B and Appendix C, respectively.
} 


\subsection{Households}

There is a large number of households whose preferences over consumption goods are described as

$$
\mathbb{E}_{0} \sum_{t=0}^{\infty} \beta^{t} U\left(c_{t}\right),
$$

where $c_{t}$ is consumption. The period utility function $U$ is strictly increasing and strictly concave. The parameter $\beta$ denotes the discount factor, with $0<\beta<1$, and $\mathbb{E}_{0}$ is the expectation operator. The consumption good is an aggregator of tradable consumption, $c_{t}^{T}$, and non-tradable consumption, $c_{t}^{N}$. The aggregation technology exhibits constant-elasticityof-substitution and it is specified as

$$
c_{t}=\left(a\left(c_{t}^{T}\right)^{\frac{\varepsilon-1}{\varepsilon}}+(1-a)\left(c_{t}^{N}\right)^{\frac{\varepsilon-1}{\varepsilon}}\right)^{\frac{\varepsilon}{\varepsilon-1}}, \text { with } \varepsilon>1
$$

Households do not have direct access to international financial markets, but they receive transfers $T_{t}$ from the government which borrows and saves on their behalf in international financial markets. ${ }^{10}$ The budget constraint of each household is expressed as

$$
P_{t}^{T} c_{t}^{T}+P_{t}^{N} c_{t}^{N}=P_{t}^{T} \tilde{y}_{t}^{T}+W_{t} l_{t}+T_{t}+\Phi_{t}
$$

At households' budget constraint $P_{t}^{T}$ and $P_{t}^{N}$ denote the nominal prices of the tradable- and non-tradable goods respectively. We assume that the households' endowment of tradable goods, $\tilde{y}_{t}^{T}$, follows an exogenously determined stochastic process, that is taken as given by every household. The variable $W_{t}$ is the nominal wage rate earned from providing labor services in the non-tradable good sector. The variable $l_{t}$ is the hours worked by a household. Finally, $\Phi_{t}$ is the nominal profits received from the ownership of firms which produce the non-tradable good.

Households inelastically supply $\bar{l}$ hours to the labor market, but they may not be able to sell every labor-hour that they are endowed with: the model generates involuntary unemployment in equilibrium whenever $W_{t}$ is too high. This nominal wage rigidity is the key for the dynamic behavior of the economy, which gives rise to the following constraint

$$
l_{t} \leq \bar{l} .
$$

Households take $P_{t}^{T}, P_{t}^{N}, W_{t}, l_{t}, \Phi_{t}, T_{t}$ as given and maximize (1) subject to (2), (3), (4),

\footnotetext{
${ }^{10}$ The transfers could also be negative, in which case they constitute lump-sum taxes.
} 
and the exogenous output process for tradables - to be specified below - by choosing contingent plans $\left\{c_{t}^{T}, c_{t}^{N}\right\}$. The optimality condition for tradable and non-tradable good consumption gives

$$
\mathcal{P}_{t}=\frac{1-a}{a}\left(\frac{c_{t}^{T}}{c_{t}^{N}}\right)^{\frac{1}{\varepsilon}}
$$

where $\mathcal{P}_{t} \equiv P_{t}^{N} / P_{t}^{T}$ is the price of non-tradable goods relative to tradable goods.

\section{$3.2 \quad$ Firms}

Non-tradable output of the SOE is produced by perfectly competitive firms. Each firm operates a production technology specified as

$$
y_{t}^{N}=F\left(l_{t}\right)
$$

where $F($.$) is strictly increasing and strictly concave. Firms demand labor hours from house-$ holds to maximize profits given by

$$
\Phi_{t}=P_{t}^{N} F\left(l_{t}\right)-W_{t} l_{t}
$$

The optimality condition associated with firms' maximization problem yields $P_{t}^{N} F^{\prime}\left(l_{t}\right)=$ $W_{t}$. Dividing both sides of this expression by $P_{t}^{T}$ gives

$$
\mathcal{P}_{t} F^{\prime}\left(l_{t}\right)=w_{t}
$$

with $w_{t} \equiv W_{t} / P_{t}^{T}$ denoting the real wage denominated in terms of tradables.

\subsubsection{Downward Nominal Rigidity}

Following $\mathrm{Na}$ et al. (2018) and Schmitt-Grohé and Uribe (2016) we assume that wages are downwardly rigid. Specifically, there is a lower bound on the growth rate of equilibrium nominal wages such as

$$
W_{t} \geq \gamma W_{t-1}, \gamma>0
$$

The parameter $\gamma$ captures the degree of downward nominal wage rigidity. The higher is $\gamma$, the more rigid are the nominal wages. As also argued by Schmitt-Grohé and Uribe (2016), downward wage rigidity is a stylized empirical fact especially for the case of the 
European Economic and Monetary Union: in early 2000s euro-area countries experienced substantial appreciations in hourly wages, caused mostly by large increases in capital inflows. Following the drying up of capital inflows at the onset of the 2007/2008 global financial crisis, aggregate demand collapsed. However, hourly wages in the post-2008 era remained at the peak-level that they achieved before 2008. The combination of falling demand and rigid wages, together with the absence of local currencies that can be depreciated during the downturn, led to massive increases in involuntary unemployment throughout the eurozone, especially in peripheral countries.

The presence of downward rigidity in nominal wages gives rise to involuntary unemployment in our model as in Na et al. (2018) and Schmitt-Grohé and Uribe (2016), such that $\bar{l}-l_{t}>0$ is a frequent feature of the economy whose dynamic implications we investigate. Specifically, nominal rigidities imply a complementary slackness condition in the form of $\left(\bar{l}-l_{t}\right)\left(W_{t}-\gamma W_{t-1}\right)=0$, which could be also expressed as

$$
\left(\bar{l}-l_{t}\right)\left(w_{t}-\gamma w_{t-1} \frac{P_{t-1}^{T}}{P_{t}^{T}}\right)=0 .
$$

The condition (10) implies that periods of unemployment are always accompanied with a binding nominal wage constraint.

\subsubsection{Partial Equilibrium in Labor and Goods Markets}

The first requirement of the competitive equilibrium is that the market for non-traded goods clears in all periods, such that

$$
c_{t}^{N}=y_{t}^{N}
$$

for all $t$.

We denote the foreign price of tradables with $P_{t}^{*}$ and assume that the law of one price holds for tradables

$$
P_{t}^{T}=P_{t}^{*} \tilde{\epsilon}_{t}
$$

where $\tilde{\epsilon}_{t}$ is the nominal exchange rate defined as the domestic currency price of one unit of foreign currency. As long as the country is a member of the monetary union, the nominal exchange rate is simply given by $\tilde{\epsilon}_{t}=1$. Furthermore, we assume that the foreign price of 
tradables is fixed and set at $P_{t}^{*}=1$ such that

$$
P_{t}^{T}= \begin{cases}1, & \text { if the country remains in the union } \\ \epsilon_{t}, & \text { if the country is outside the union }\end{cases}
$$

where $\epsilon_{t}$ is to be determined at the discretion of the domestic government following upon a potential exit of the SOE from the monetary union. Plugging the above into equation (10) yields a modified slackness condition

$$
\left(\bar{l}-l_{t}\right)\left(w_{t}-\gamma w_{t-1} \frac{\tilde{\epsilon}_{t-1}}{\tilde{\epsilon}_{t}}\right)=0
$$

The partial competitive equilibrium in labor and goods markets is a result of firms and households making optimal decisions and interacting by taking the tradable endowment process and the policies of the government as given. We define the partial competitive equilibrium as follows.

Definition (Partial Competitive Equilibrium). A partial competitive equilibrium is a set of stochastic processes $\left\{c_{t}^{T}, c_{t}^{N}, c_{t}, l_{t}, W_{t}, P_{t}^{N}, P_{t}^{T}\right\}$ satisfying (2), (3), (4), (5), (6), (8), (9), (11), (14), given the processes $\left\{\tilde{y}_{t}^{T}, \tilde{\epsilon}_{t}, T_{t}\right\}$ and the initial condition $w_{0}$.

\subsection{Government}

The key economic actor in the model is the government of the SOE. In every period, the government decides on the external borrowing of the country in international financial markets and also whether to default on its outstanding external debt. The government also decides whether to retain the membership of the SOE in a monetary union - governed by a fixed exchange rate regime - and if it decides to exit the union, it also chooses the follow-up exchange rate policy of the country. At first we present the possible regimes that the SOE can start any time-period with, depending on the government's past external-debt-default and union-exit decisions, and then delineate the decision processes of the government that lead to these regimes.

At the beginning of a period $t$ the country may be in one of four possible regimes. The SOE can be in the monetary union while being either in good financial standing - as of the beginning of the period $t$, or while being in the default-status if the government reneged on its external debt at some point in time before period $t$. The SOE might have also exited the 
monetary union before the time period $t$ and have the exit status in period $t$ either while having a good financial standing or while being in the default status.

The full set of possible transitions between different regimes is presented graphically in Figure 2. The SOE in the UNION regime is a member of the monetary union with full access to international financial markets. While being in the UNION regime the government can retain the country in this regime by keeping membership in the currency union and at the same time continue to honor the country's external debt obligations. The government can also move the SOE into one of the three remaining regimes by fully defaulting on its entire outstanding debt (the regime we denote as DEFAULT), by exiting the union (the regime denoted as EXIT) or by defaulting fully and at the same exiting the monetary union (the regime denoted as $A U T A R K Y) .{ }^{11}$ We turn next to delineating the decision processes of the government and their economic implications that give rise to these four possible regimes.

Figure 2: Possible regime switches in the economy

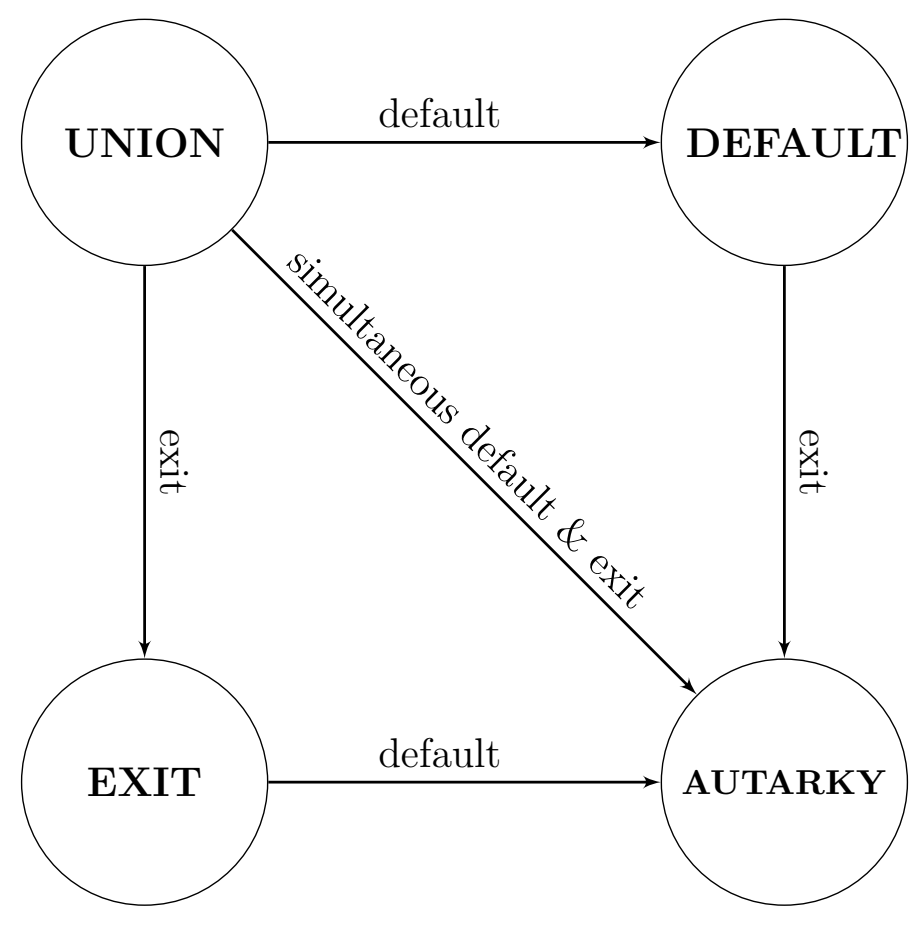

\footnotetext{
${ }^{11}$ For tractability we omit the possibility that once a country defaults it may reenter the international financial markets. The reentry assumption is standard in the literature and allows to match better the moments observed in the data, but does not qualitatively change the properties of our model. The Bellman equations and the scheme of regime switches for the case with reentry can be found in the Technical Appendix available from the corresponding author upon request.
} 


\subsubsection{Government's International Financial Market Policies}

As long as the government of the SOE is in good financial standing - such that a default on its external debt had never been executed before, it can issue one-period, non-state contingent bonds and raise funds in international markets. The bonds are sold at the nominal price $q_{t}$, denominated in terms of the domestic currency of the country. This means that for the case of a union-member the external debt is denominated in terms of the union-currency whereas for a country outside the union debt is denominated in terms of the country's own domestic currency. The legal framework (as in the case of eurozone) allows the government to switch the denomination of the SOE's debt from the union-currency to the SOE's own currency following upon an exit from the union. The face value of the government bond, $d_{t+1}$, specifies the value that needs to be repaid in the next period. The government uses the funds raised in international financial markets to provide transfers to the households $\left(T_{t}\right)$. The intertemporal budget constraint of the government is expressed as

$$
T_{t}=\left(q_{t} d_{t+1}-d_{t}\right)\left(1-\mathcal{D}_{t}\right)
$$

where $\mathcal{D}_{t}$ is the default history up to (and including) period $t$, where $\mathcal{D}_{t}=0$ indicates no default up until period $t$, and $\mathcal{D}_{t}$ takes the value 1 if a default has taken place in period $t$ or in any of the preceding periods. We distinguish between the default history $\mathcal{D}_{t}$ and the default decision $D_{t}$. The latter takes on the value $D_{t}=1$ only in the period of default and 0 in all remaining periods, and the history takes the value 1 in all periods starting from the default period. ${ }^{12}$

If the government decides to default on its external debt $\left(D_{t}=1\right)$ in a period $t$, in that particular period the entire debt repayment obligations of SOE to the foreign lenders do not get honored. Following the incidence of a default in $t$, in the same period $t$ the government loses its access to international financial markets and this exclusion remains effective forever. As standard in the literature on sovereign debt and default, we assume that in any timeperiod after SOE switches to the bad financial standing $\left(\mathcal{D}_{t}=1\right)$, it suffers an output loss worth of $L\left(y_{t}^{T}\right)$ with $L() \geq$.0 and $L^{\prime}(.) \geq 0 .{ }^{13}$ This means that the flow of tradables available to households is equal to

$$
\tilde{y}_{t}^{T}=y_{t}^{T}-\mathcal{D}_{t} L\left(y_{t}^{T}\right)
$$

\footnotetext{
${ }^{12}$ The relationship between $\mathcal{D}_{t}$ and $D_{t}$ can be described by $1-\mathcal{D}_{t}=\prod_{i=0}^{t}\left(1-D_{i}\right)$, i.e. the default history $\mathcal{D}_{t}$ takes on the value 0 if and only if the default decision was 0 (i.e. repay) in all periods from 0 up to $t$.

${ }^{13}$ Mendoza and Yue (2012) provide a theoretical microfoundation for the output loss after default and document its empirical validity.
} 
where the basic endowment $y_{t}^{T}$ follows an $\operatorname{AR}(1)$ process

$$
\ln \left(y_{t}^{T}\right)=\rho \ln \left(y_{t-1}^{T}\right)+(1-\rho) \ln \left(y^{T}\right)+\mu_{t}
$$

with $y^{T}$ denoting the steady-state level of tradable output.

\subsubsection{Government's Nominal Exchange Rate Policies}

The SOE starts out as a member of the monetary union. This means that the SOE initially operates under an extreme version of an exchange rate peg: it uses the currency of the monetary union as its domestic currency, which implies an exchange rate fixed at $\tilde{\epsilon}=1$. The only way for the government to deviate from this exchange rate is to exit the union and introduce its own domestic currency. As long as the SOE is a member of the union, the government undertakes a decision at the beginning of every period whether to remain as a member state in that particular period or to exit the union and set the exchange rate of the country equal to $\epsilon_{t}$ at its own discretion. The government's "remain-or-exit decision" is a discrete choice denoted by $X_{t}$, with $X_{t}=0$ indicating "to remain" in the union in period $t$ and $X_{t}=1$ indicating "to exit" from the union in period $t$ in order to introduce SOE's own domestic currency as of period $t$. We assume that once the SOE exits the union it cannot reenter. ${ }^{14}$

Next to the exit decision $X_{t}$, we introduce also a variable representing the exit history of the $\operatorname{SOE} \mathcal{X}_{t}$. We use $\mathcal{X}_{t}=0$ to indicate a country that has never exited and thus remains a member state of the union, and $\mathcal{X}_{t}=1$ to indicate a country outside of the union, i.e. a country that has executed an exit in period $t$ or in any preceding period.

As an important feature of the model we assume costly union-exit. Costly exit means that abandoning the currency of the union as the domestic-currency of the SOE is associated with a one-time loss of $\tilde{C}$ units of utility in the period of exit. The one-time utility loss associated with exiting the monetary union is additive and therefore it does not interact with the utility from consuming tradable and non-tradable goods. One can easily motivate this monetaryunion exit cost, because it requires time and effort in order to legally abandon a currency and switch to another one by replacing the old one at all transactions. It is also standard in the currency crises literature to assume that abandoning a currency-peg is a costly decision, where as in our framework in some studies the cost of abandoning the peg is incorporated

\footnotetext{
${ }^{14}$ This assumption helps with tractability but does not affect our qualitative or quantitative findings. It is unclear whether a country exiting the EMU would be allowed to rejoin in the future.
} 
as a utility loss. ${ }^{15}$

What distinguishes the monetary union exit cost from the cost of abondoning a standard currency-peg is that the former is expected to be governed by a large uncertainty because of the necessity to literally replace the currency used in transactions, which - as a key and novel feature - we also incorporate into our model.

The motivation for the cost-uncertainty can be twofold: First, as in the case of the euro area, to improve the credibility of the union, the founders might have decided not to include any explicit legal exit-clause, making any potential exit uncertain and changing the unilateral decision of currency abandonment into a multilateral negotiation process between the country exiting and the remaining members of the union. Second, since no country ever exited a monetary union (as is also the case for the euro area), there is no past experience that a decision-maker government could exploit to precisely estimate the cost of the union-exit. ${ }^{16}$

How difficult the implementation of an exit is going to be, gets understood ex-post - only upon the completion of a de-facto exit from the union. Therefore, the first exit from the union provides a valuable case study for other member states which might consider to exit in the future. In order to capture this important aspect of monetary-union membership, we assume that the utility cost of exit is uncertain until the first-exit. After the completion of the first-time exit, the cost figure gets revealed to all member states and remains at that level forever. This means that if the government of the SOE whose behavior we investigate wants to implement a first-time exit from the union, it has to form beliefs about $\tilde{C}$. The beliefs about the exit cost are given by a distribution function $G(C)$ and they are shared by all economic actors of the model. There are two exogenous shocks at the union level concerning the revelation of the true $\tilde{C}$, which influence economic decisions and outcomes for the SOE and importantly also for its external lenders. We formalize them as follows.

We describe the state of the monetary union in any time period $t$ from the perspective of the SOE, by excluding the actions of the SOE and their implications on the rest of the monetary union. This is how we isolate and study the effects of "exogenous shocks" stemming from the monetary-union on the macroeconomic dynamics of the SOE.

The overall state of the monetary union, from the SOE's perspective, as of the beginning

\footnotetext{
${ }^{15}$ Obstfeld $(1994,1996,1997)$ are prominent examples of currency crises models where the cost of abandoning the peg is introduced as an additive utility term.

${ }^{16}$ The uncertainty governing the economic and political costs of Brexit may serve as an example of how difficult it is to predict the consequences of an exit from any union, if it is unprecedented. This is despite the fact that there is a legal clause for exiting the EU as compared to the lack of a clause for the EMU-exit. Another argument for the uncertainty of the exit cost in the case of the EMU is the fact that it is unsure whether a country exiting the EMU would be also forced to exit the EU.
} 
of any time period $t$ is described by the vector $\mathcal{M}_{t}$. The state of the union $\mathcal{M}_{t}$ is an information-set containing the past-history of "exits" from the union until period $t$ (denoted with $h_{t}$ ) and the current-period news associated with the existence of a member state seeking an option to exit, which we call as "exit rumors" (denoted with $e_{t}$ ). In this respect, $\mathcal{M}_{t}=$ $\left(h_{t}, e_{t}\right)$.

To the end of exit-histories, there are two potential histories relevant for the SOE: the existence of at least one member state - other than the SOE - that departed from the union before period $t$ (a state of the history which we denote with $x$ ); and, the absence of any exit until period $t$ (a state of history denoted by $u$ ). Hence, $h_{t} \in \mathcal{H}_{t} \equiv\{x, u\}$ for all $t$. Exit shocks get realized as of the end of each period. This means the exit of a member state which affects the relevant monetary-union history for the SOE in period $t$ gets realized at the end of period $t-1$.

With respect to the exit-rumors stemming from one of the other members of the union in period $t$, there are also two relevant states for the SOE: the existence of at least one member state - again other than the SOE - considering an exit in period $t$ (denoted with the state $s$ ) and the absence of a member state seeking an exit (denoted with the state $n$ ). Therefore, $e_{t} \in \mathcal{E}_{t} \equiv\{s, n\}$ for all $t$.

Next we specify the transition of the realized states in period $t, \mathcal{M}_{t}=\left(h_{t}, e_{t}\right)$, into the future states of period $t+1, \mathcal{M}_{t+1}=\left(h_{t+1}, e_{t+1}\right)$. We first note that $x$ is an absorbing state for the case of historical transitions, i.e. $\operatorname{prob}\left(h_{t+1}=x \mid h_{t}=x\right)=1$ for any $e_{t} \in\{s, n\}$. This means that once a first-exit from the union is realized, the arrival of exit rumors after that first-exit become inconsequential for union-wide economic outcomes. The likelihood of transitioning from history $h_{t}=u$ to history $h_{t+1}=x$ depends though on the existence of exit rumors in period $t$. To this end, we assume that

$$
\operatorname{prob}\left(h_{t+1}=x \mid h_{t}=u, e_{t}=s\right)=p>\operatorname{prob}\left(h_{t+1}=x \mid h_{t}=u, e_{t}=n\right)=0,
$$

which implies that if there are exit-rumors about at least one member-state's potential departure in period $t$, the (first) actual exit from the union will materialize as of the end of period $t$ with probability $p$. If there are no exit-rumors in the union (excluding any exitintentions that the SOE might have), no exit would materialize in the same period, and hence in this case the union would remain into the next period as a whole as long as the SOE does not execute an exit on its own. Therefore, superscripting the next period states with primes, the probability transition matrix for the state of histories of the monetary-union 
that the SOE will take as given $\left(\Omega\left(h^{\prime}=x \mid \mathcal{H}, \mathcal{E}\right)\right)$ is expressed as

$$
\Omega\left(h^{\prime}=x \mid \mathcal{H}, \mathcal{E}\right)=\left[\begin{array}{ll}
\operatorname{prob}(x \mid x, s) & \operatorname{prob}(x \mid x, n) \\
\operatorname{prob}(x \mid u, s) & \operatorname{prob}(x \mid u, n)
\end{array}\right]=\left[\begin{array}{ll}
1 & 1 \\
p & 0
\end{array}\right] .
$$

With respect to the transition of exit-rumors from one period to the next, we assume that $\operatorname{prob}\left(e_{t+1}=s \mid e_{t}=s\right)=\tilde{p}_{s}$ and $\operatorname{prob}\left(e_{t+1}=s \mid e_{t}=n\right)=\tilde{p}_{n}$ for all $h \in\{x, u\}$. Hence:

$$
\Lambda\left(e^{\prime}=s \mid \mathcal{H}, \mathcal{E}\right)=\left[\begin{array}{ll}
\operatorname{prob}(s \mid x, s) & \operatorname{prob}(s \mid x, n) \\
\operatorname{prob}(s \mid u, s) & \operatorname{prob}(s \mid u, n)
\end{array}\right]=\left[\begin{array}{ll}
\tilde{p}_{s} & \tilde{p}_{n} \\
\tilde{p}_{s} & \tilde{p}_{n}
\end{array}\right]
$$

with $\tilde{p}_{s}>\tilde{p}_{n}$. The exit-rumor shocks and their consequences for an actual exit at the unionlevel imply the potential of the revelation of the actual exit cost in the short-run, which has important theoretical and quantitative effects, as we will discuss below.

If the government of the SOE exits the union by taking the available exit-cost figures as given, effectively in the same period of the exit it introduces its own domestic currency. In this case it may also find it optimal to devalue the new currency against the currency of the union in order to relax the burden associated with a binding nominal-wage rigidity constraint. As it is apparent from equation (14), whenever the wage part of the slackness condition is binding, the government may eliminate involuntary unemployment by relaxing the constraint with a devaluation. The optimal devaluation strategy for a small open economy with nominal wage rigidities is discussed extensively in Schmitt-Grohé and Uribe (2016) and Na et al. (2018), in which the authors show that devaluations are desirable during economic contractions and default episodes.

In our framework, a devaluation has a second role. Since the government of the SOE issues bonds under the domestic law, the denomination of the external debt may be converted into the domestic currency upon exiting the monetary union. If the union-exit is followed by a devaluation and debt conversion, the exit is then equivalent to a partial default. This is costly for external lenders, because the value of debt remains constant in the newly introduced local currency, but the currency itself loses value as expressed in tradables or the union's currency. ${ }^{17}$ This partial default of the government through devaluation and debt-conversion can be executed only once, only in the period of the SOE's exit from the monetary union. In any time-period following the period of the exit the SOE issues inflation-indexed bonds,

\footnotetext{
${ }^{17}$ Schumacher et al. (2015) show that most government bonds in the eurozone were issued under domestic law, and that the risk of a conversion was priced in by international investors during the crisis. They also document that the crisis-hit-countries have used foreign law issuance after the crisis to reenter credit markets.
} 
which is equivalent to the bonds being denominated in tradables or a foreign currency.

$\mathrm{Na}$ et al. (2018) show also that a decision-maker government is indifferent between any devaluation that is larger than the minimal devaluation guaranteeing full employment. Since in our model the devaluation has the additional partial default effect, the government would always choose an infinite devaluation to wipe away all debt. To prevent this we assume that the government is limited to choosing the minimal devaluation a la Na et al. (2018). This assumption is made for simplicity and transparency, as alternatively we could assume an exit cost that is dependent on the size of the devaluation.

\subsubsection{Value Functions and Government's Optimization Program}

Let us denote with $\mathcal{S}_{t}$ the state of the SOE in period $t$. The state of the country encompasses the exogenous endowment process $\tilde{y}_{t}^{T}$, the past equilibrium wage rates, as well as the past debt, exchange rate, default and exit decisions of the government, so that $\mathcal{S}_{t}=\left\{\tilde{y}_{t}^{T}, W_{t-1}, d_{t}, \epsilon_{t-1}, \mathcal{D}_{t-1}, \mathcal{X}_{t-1}\right\}$. The government's objective is to maximize the households' expected lifetime utility by taking $\mathcal{S}_{t}$ and the state of the monetary union, $\mathcal{M}_{t}$, and the conditions described in the definition of partial equilibrium as given. As delineated above, the policy instruments of the government are fourfold: (i) the government decides on whether to keep the country in the monetary union and (ii) following upon an exit the nominal exchange rate of its newly introduced currency. (iii) The government also undertakes a decision on whether to default on the country's external debt and (iv) in any time-period of good financial standing it chooses the level of external debt for the next period.

The value function for an $\mathrm{SOE}$ in the UNION regime at the beginning of period $t$ is

$$
\begin{aligned}
V^{U}\left(\mathcal{S}_{t} ; \mathcal{M}_{t}\right)= & \max _{c_{t}, d_{t+1}, D_{t}, X_{t}}\left\{u\left(c_{t}\right)+\left(1-D_{t}\right)\left(1-X_{t}\right) \beta \mathbb{E}_{t}\left[V^{U}\left(\mathcal{S}_{t+1} ; \mathcal{M}_{t+1}\right)\right]\right. \\
& +\left(1-D_{t}\right) X_{t}\left(\beta \mathbb{E}_{t}\left[V^{X}\left(\mathcal{S}_{t+1} ; \mathcal{M}_{t+1}\right)\right]-\tilde{C}\right) \\
& +D_{t}\left(1-X_{t}\right) \beta \mathbb{E}_{t}\left[V^{D}\left(\mathcal{S}_{t+1} ; \mathcal{M}_{t+1}\right)\right] \\
& \left.+D_{t} X_{t}\left(\beta \mathbb{E}_{t}\left[V^{A}\left(\mathcal{S}_{t+1} ; \mathcal{M}_{t+1}\right)\right]-\tilde{C}\right)\right\}
\end{aligned}
$$

subject to (3) and (15). We note that the value associated with being a member of the union $\left(V^{U}\left(\mathcal{S}_{t} ; \mathcal{M}_{t}\right)\right)$ in period $t$ takes into account the possibility of leaving the union in the same time period by incurring the one-time (additive) utility loss of $\tilde{C}$. We also highlight that since the utility loss from exiting the union is additive, it does not interact with the

utility from consumption in the expression of the value function. Furthermore, $V^{X}$ is the 
value function for an SOE in the EXIT regime at the beginning of period $t$, which can be represented as

$$
\begin{aligned}
V^{X}\left(\mathcal{S}_{t} ; \mathcal{M}_{t}\right)= & \max _{c_{t}, d_{t+1}, \epsilon_{t}, D_{t}}\left\{u\left(c_{t}\right)+\left(1-D_{t}\right) \beta \mathbb{E}_{t}\left[V^{X}\left(\mathcal{S}_{t+1} ; \mathcal{M}_{t+1}\right)\right]\right. \\
& \left.+D_{t} \beta \mathbb{E}_{t}\left[V^{A}\left(\mathcal{S}_{t+1} ; \mathcal{M}_{t+1}\right)\right]\right\}
\end{aligned}
$$

subject to (3) and (15). $V^{D}$ is the value function for an SOE in the DEFAULT regime at the beginning of period $t$

$$
\begin{aligned}
V^{D}\left(\mathcal{S}_{t} ; \mathcal{M}_{t}\right)= & \max _{c_{t}, X_{t}}\left\{u\left(c_{t}\right)+\left(1-X_{t}\right) \beta \mathbb{E}_{t}\left[V^{D}\left(\mathcal{S}_{t+1} ; \mathcal{M}_{t+1}\right)\right]\right. \\
& \left.+X_{t}\left(\beta \mathbb{E}_{t}\left[V^{A}\left(\mathcal{S}_{t+1} ; \mathcal{M}_{t+1}\right)\right]-\tilde{C}\right)\right\}
\end{aligned}
$$

subject to (3) and (15), where $V^{D}\left(\mathcal{S}_{t} ; \mathcal{M}_{t}\right)$ in period $t$ takes into account the possibility of incurring the utility loss associated with the monetary union exit in the same time period. Finally, $V^{A}$ is the value function for an SOE in the AUTARKY regime at the beginning of period $t$

$$
V^{A}\left(\mathcal{S}_{t} ; \mathcal{M}_{t}\right)=\max _{c_{t}, \epsilon_{t}}\left\{u\left(c_{t}\right)+\beta \mathbb{E}_{t}\left[V^{A}\left(\mathcal{S}_{t+1} ; \mathcal{M}_{t+1}\right)\right]\right\}
$$

subject to (3) and (15).

\subsection{External Lenders}

The bonds issued by the government of the SOE are traded in international financial markets. The external (foreign) lenders buying these bonds are assumed to be risk neutral. With $r^{*}$ denoting the risk free interest rate, the no-arbitrage condition for sovereign bonds under the UNION regime takes the form of

$$
1+r^{*}=\frac{1}{q_{t}} \mathbb{E}_{t}\left[\left(1-D_{t+1}\right)\left(1-X_{t+1} \frac{\tilde{\epsilon}_{t}}{\tilde{\epsilon}_{t+1}}\right) \mid \mathcal{D}_{t}=0, \mathcal{X}_{t}=0\right]
$$

This condition states that external lenders demand a premium for the possibility of an outright default as well as for the possibility of a partial default through debt-conversion. Put differently, the price of the SOE-bonds depends on the probability of the SOE remaining in the UNION regime. As also delineated in the government's program, the partial-default channel that raises the cost of borrowing in international financial markets is novel for this class of models. Finally, the expectation formation of external lenders is key for our analysis, 
which among other things is also conditional on shocks to tradables and importantly on shocks to the state of the union concerning the revelation of the union-exit cost.

A similar no-arbitrage condition for government bonds holds for a country in the EXIT regime

$$
1+r^{*}=\frac{1}{q_{t}} \mathbb{E}_{t}\left[1-D_{t+1} \mid \mathcal{D}_{t}=0, \mathcal{X}_{t}=1\right],
$$

where under the EXIT regime the bonds are inflation-indexed and thus investors do not face any exchange rate risk.

\subsection{Qualitative Properties of the Model}

The probability of transitioning from history- $u$ (no past exits) to history- $x$ (with exits) at the level of the union in-between any two periods and the dependence of this transition probability on exit-rumors affect the decisions of the SOE that are intertemporally relevant, such as the borrowing of the SOE's government in international financial markets. The key mechanism that gives rise to this important property is related to the "potential resolution" of the cost-uncertainty in the short-run. We illustrate the mechanism as follows.

Let us consider the following distribution function of ex-ante beliefs associated with the union-exit utility loss, $G(C)$, that is shared by the SOE's government and the external lenders

$$
\tilde{C}= \begin{cases}C^{L}, & w / \text { prob. } \zeta \\ C^{H}, & w / \text { prob. } 1-\zeta\end{cases}
$$

with $C^{L}<C^{H}$ and an implied expected value of $C^{e}=\zeta C^{L}+(1-\zeta) C^{H}$. Furthermore, without loss of generality let us also assume that the exit rumors shock does not exhibit time-series persistence (i.e. $\left.\tilde{p}_{s}=0\right){ }^{18}$

Given an arbitrary state of the SOE and the state of the monetary-union in period $t, \mathcal{S}_{t}$ and $\mathcal{M}_{t}$, we can express the following probabilities: ${ }^{19}$

$$
\begin{aligned}
\operatorname{prob}_{t}\left(X_{t+1}=1 \mid \mathcal{S}_{t} ; u, n\right) & =\operatorname{prob}_{t}\left(X_{t+1}=1 \mid \mathcal{S}_{t} ; G(C)\right) \\
\operatorname{prob}_{t}\left(X_{t+1}=1 \mid \mathcal{S}_{t} ; u, s\right) & =p\left[\zeta \operatorname{prob}_{t}\left(X_{t+1}=1 \mid \mathcal{S}_{t} ; C^{L}\right)+(1-\zeta) \operatorname{prob}_{t}\left(X_{t+1}=1 \mid \mathcal{S}_{t} ; C^{H}\right)\right]
\end{aligned}
$$

\footnotetext{
${ }^{18}$ Assuming $\tilde{p}_{s}>0$ would reinforce the qualitative results presented in this section further in expense of notational burden.

${ }^{19}$ We would like to note that $\operatorname{prob}_{t}\left(X_{t+1}=1 \mid \mathcal{S}_{t} ; u, n\right)>0$ is a theoretical possibility for the SOE, although - at the level of the monetary union in the absence of current exit-rumors - the exit of any other member state is not possible.
} 


$$
+(1-p) \operatorname{prob}_{t}\left(X_{t+1}=1 \mid \mathcal{S}_{t} ; C^{e}\right) .
$$

Thanks to the additive nature of the exit-utility loss we can simplify equation 27 to the form

$$
\operatorname{prob}_{t}\left(X_{t+1}=1 \mid \mathcal{S}_{t} ; u, n\right)=\operatorname{prob}_{t}\left(X_{t+1}=1 \mid \mathcal{S}_{t} ; C^{e}\right)
$$

We can immediately observe that if

$$
\zeta \operatorname{prob}_{t}\left(X_{t+1}=1 \mid \mathcal{S}_{t} ; C^{L}\right)+(1-\zeta) \operatorname{prob}_{t}\left(X_{t+1}=1 \mid \mathcal{S}_{t} ; C^{H}\right) \neq \operatorname{prob}_{t}\left(X_{t+1}=1 \mid \mathcal{S}_{t} ; C^{e}\right)
$$

then an "exit-rumors shock" at the union-level in period $t$ would have an effect on the government's probability to exit the union in period $t+1$. Importantly, as a relevant case for our analysis, given a particular $\mathcal{S}_{t}$ if decision-makers would set their expectations such that

$$
\begin{aligned}
& \operatorname{prob}_{t}\left(X_{t+1}=1 \mid \mathcal{S}_{t} ; C^{e}\right)=0, \text { and } \\
& \operatorname{prob}_{t}\left(X_{t+1}=1 \mid \mathcal{S}_{t} ; C^{L}\right)>0,
\end{aligned}
$$

then (30) and (31) imply

$$
\operatorname{prob}_{t}\left(X_{t+1}=1 \mid \mathcal{S}_{t} ; u, s\right)>\operatorname{prob}_{t}\left(X_{t+1}=1 \mid \mathcal{S}_{t} ; u, n\right)
$$

for any $p, \zeta>0$, because $p \zeta \operatorname{prob}_{t}\left(X_{t+1}=1 \mid \mathcal{S}_{t} ; C^{L}\right)>0$ for all $p, \zeta>0$ and $\mathcal{S}_{t}$ that we concentrate on. Hence, we obtain the following important qualitative property.

Proposition 3.1 If conditions (30) and (31) hold, then an exit-rumors shock in period $t$ increases the likelihood of the SOE exiting the union in period $t+1$.

The intrinsic motivation for the government of the SOE to consider an exit from the union is associated with the benefits from setting the nominal exchange rate independently as such to devalue its own domestic currency relative to the currency of the monetary union. Specifically, in our framework, as in Schmitt-Grohé and Uribe (2016) and Na et al. (2018), the downward nominal rigidity in wages induces currency devaluation to be desirable during economic downturns in order to relieve the burden of unemployment and to reduce the output losses caused by a strong exchange-rate peg. The key feature distinguishing our model from these two studies is that in our set-up devaluation is not a costless action, because in our 
framework the country needs to exit the monetary union first to be able to devalue. ${ }^{20}$ As an immediate implication of our model, we formalize the following key remark.

Remark. Since the fundamental reason that motivates paying the exit cost $\tilde{C}$ is to devalue the currency, in our framework departing from the union always comes along with a currency devaluation and a follow-up debt conversion.

This property creates immediate implications of an exit-rumors shock for the cost of external borrowing. Specifically, let us first assume that the government cannot (fully) default on its external debt, such that $D_{t}=0$ for all $t$. However, partial default is still possible and upon exiting the union, the government is expected to execute it with certainty as highlighted in the remark above. The price of external debt in period $t\left(q_{t}\right)$ is determined by equation (24), which takes the probability of a devaluation between periods $t$ and $t+1$ into account. Then, for those $\mathcal{S}_{t}$ for which (30) and (31) hold, we have

$$
q_{t}\left(\mathcal{S}_{t} ; u, s\right)<q_{t}\left(\mathcal{S}_{t} ; u, n\right)
$$

The property (32) arises, because (i) in the period of a monetary-union exit the government devalues its currency, which affects the repayment of external borrowers, and (ii) if (30) and (31) are satisfied, the exit-rumors shock generates a likelihood of exiting the union over the near-horizon for the SOE. Therefore, at the onset of a "Grexit" type rumors - without necessarily the realization of an actual exit - the borrowing interest rates $\left(1 / q_{t}\right)$ are expected to rise also for countries which did not necessarily experience a drastic deterioration in country-specific fundamentals. This property helps us to qualitatively capture the stylized fact of rising interest rates in Southern European countries following the Greek debt crisis, as depicted in Figure 1. We summarize this important property in the next proposition.

Proposition 3.2 If conditions (30) and (31) hold, then an exit-rumors shock in period $t$ causes the interest rates to rise on newly issued SOE-bonds in period t.

This qualitative channel is re-inforced, because the government is also allowed to fully default on its debt. The intuition is as follows: the rising interest rates (or falling bond prices) caused by the heightened likelihood of an exit-and-devaluation sequence increases

\footnotetext{
${ }^{20}$ We would like to note that the downward wage rigidity is one micro-founded way of inducing devaluation to be optimal. There are other rationale why devaluation could be an optimal policy during an economic downturn. Our key mechanism does not require downward rigidities per se. What it requires is the presence of a motive to devalue the currency in certain states of the world, such that when the cost of the monetary union exit is low enough, the government would find abandoning the currency union and adopting a devalued domestic currency welfare improving.
} 
the future repayment burden for the government of the SOE, which as in any other model of sovereign default leads to a further surge in interest rates.

An important condition that gives rise to the findings of propostions 3.1 and 3.2 and one that motivates our quantitative analysis in the next section is $\operatorname{prob}_{t}\left(X_{t+1}=1 \mid \mathcal{S}_{t} ; C^{e}\right)=0$. This turns out to be an empirically well-justifiable condition: before the Greek crisis hit the eurozone, the interest rates charged on sovereign bonds of Southern European countries equaled to the risk-free interest rates charged on sovereign bonds of Germany. This we interpret as that the external lenders did not forecast any short-run possibility of a euroexit before the Greek sovereign debt trouble, which in the next section will help us in assigning a benchmark value for the expected cost of exit. Using our notation, this means that $1 / q_{t}\left(\mathcal{S}_{t} ; u, n\right)$ equaled to the risk-free interest rate, implying $\operatorname{prob}_{t}\left(X_{t+1}=1 \mid \mathcal{S}_{t} ; C^{e}\right)=0$. Moreover, as an additional motivation in the midst of the crisis the unemployment rates in Southern European countries surged and these countries fell into deep and prolonged recessionary episodes. Even then, no member state decided to exit EMU in an attempt to regain international competitiveness and to reduce unemployment.

\section{Quantitative Analysis}

In this section we parameterize the model and solve it numerically in order to explore the dynamics of the small open economy, the SOE, around the times of an exit-rumors shock. In particular we are interested in studying the adjustments in default and exit likelihood of the SOE's government following an incidence of exit-rumors in the monetary union and the reaction of external lenders to such adjustments. For this purpose at first we calibrate a baseline economy where the likelihood of exit-rumors at the union level is zero. Specifically, in the baseline quantitative framework we impose a monetary union history such that (i) there were no exits from the union in the past, (ii) there are no rumors about a future exit of a member state and (iii) the probability of such news appearing in the near future equals zero. Analyzing the behavior of an economy without past-exits and exit-rumors allows us to study decision making solely based on the SOE's country-specific shocks on tradable output, past debt decisions and the level of nominal wages in the SOE.

After having analyzed the baseline dynamics of the model, we will turn to investigating the potential of sovereign debt contagion generated by a first-time exit-rumors shock stemming from a troubled member state. For this follow-up analysis, we will conduct quantitative experiments using the calibrated framework, where we will surprise the monetary-union 
member (SOE) with the arrival of the news about a (first-time) potential departure of another member state in the near future and investigate the aggregate dynamics governing the SOE after this exit-rumors shock.

\subsection{Functional Forms and Calibration}

In Table 1 we provide the details of the benchmark parametrization of the model. Our parametrization largely resembles that of $\mathrm{Na}$ et al. (2018), where we follow their calibration for Argentina, since the quantitative analysis is meant to illustrate the dynamics of the model, rather than to replicate the actual data. Concentrating on the Argentinian calibration allows us also to consider a scenario of an Argentina-like country being a member of the EMU and going through the experience of the recent crisis. Furthermore, Argentina has a welldocumented history of modern-times defaults, contrary to any of the actual EMU members, which makes it possible to calibrate the parameters related to sovereign debt and default. The details of the model parametrization are as follows.

We fix the labor endowment to unity and set $\gamma=0.99$, which also Na et al. (2018) choose based on the evidence provided in Schmitt-Grohé and Uribe (2016), implying that nominal wages cannot fall more than 4 percent a year. To the end of functional forms, we assume a CRRA type of utility function as

$$
U(c)=\frac{c^{1-\sigma}-1}{1-\sigma}
$$

and choose $\sigma=2$. For the discount factor we assign a value of $\beta=0.87$, which is somewhat lower than the standard parametrization of the discount factor in macroeconomic models, but not unusual for an Eaton-Gersovitz type of set-up. In the consumption aggregator we assign the share of tradables as $a=0.28$ and the elasticity of substitution between tradables

and non-tradables as $\varepsilon=0.44$. For the production technology of the non-traded sector, we specify

$$
y_{t}^{N}=h_{t}^{\alpha}
$$

and assume $\alpha=0.59$. To the end of the output process, we use the Na et al. (2018) OLS estimates of (17) given by $\rho=0.932$ and $\sigma_{y}=0.037$.

We specify the output loss function that is relevant in states of default as

$$
L\left(y_{t}^{T}\right)=\max \left(0, \delta_{1} y_{t}^{T}+\delta_{2}\left(y_{t}^{T}\right)^{2}\right)
$$


Table 1: Benchmark Parametrization of the model

\begin{tabular}{ccl}
\hline \hline Parameter & Value & Description \\
\hline$\gamma$ & 0.99 & Degree of downward nominal wage rigidity \\
$\sigma$ & 2 & Inverse of intertemporal elasticity of consumption \\
$y^{T}$ & 1 & Steady-state tradable output \\
$\bar{h}$ & 1 & Labor endowment \\
$a$ & 0.28 & Share of tradables \\
$\varepsilon$ & 0.44 & Elasticity of substitution between tradables and non-tradables \\
$\alpha$ & 0.59 & Labor share in the non-traded sector \\
$\beta$ & 0.87 & Quarterly discount factor \\
$r^{*}$ & 0.01 & Quarterly net world interest rate \\
$\delta_{1}$ & -0.25 & Parameters of the output loss functions \\
$\delta_{2}$ & 0.27 & Serial correlation of ln $y_{t}^{T}$ \\
$\rho$ & 0.932 & Standard deviation of innovation to $y_{t}^{T}$ \\
$\sigma_{y}$ & 0.037 & Low exit cost \\
$C^{L}$ & 0.8 & High exit cost \\
$C^{H}$ & 3.8 & Expected cost of exit \\
$C^{e}$ & 2.3 & Probability of a rumors shock \\
$\tilde{p}_{n}$ & 0 & Discretization of the state space \\
\hline & & Number of tradable output grid points (equally spaced in logs) \\
\hline$n_{y}$ & 31 & Number of debt grid points (equally spaced) \\
$n_{d}$ & 101 & Number of wage grid points (equally spaced in logs) \\
$n_{w}$ & 151 & Grid for tradable output \\
{$\left[\underline{y}^{T}, \bar{y}^{T}\right]$} & {$[0.65,1.53]$} & Grid for external debt \\
{$[\underline{d}, \bar{d}]$} & {$[-0.5,1.25]$} &
\end{tabular}

and set $\delta_{1}=-0.25$ and $\delta_{2}=0.27$. These parameters are chosen to achieve a default frequency of 1.8 times a century under a flexible exchange rate regime. ${ }^{21}$ We choose the risk-free rate as $r^{*}=0.01$ per quarter, a commonly assigned value in the literature.

Finally, we specify the expected utility cost of exiting the monetary union and the "highcost" and "low-cost" realizations of this exit cost. The calibration of these parameters is challenging, as no country has ever exited the EMU. We use this observation to choose a benchmark expected cost of exit, such that exit does not happen in simulations in which the SOE takes the expected utility cost figure as given. We choose the low cost realization in

\footnotetext{
${ }^{21}$ The default frequency implied by our framework is somewhat lower than the actual value for Argentina of 2.6, and the values for $\delta_{1}$ and $\delta_{2}$ differ from the values chosen by $\mathrm{Na}$ et al. (2018). The lower penalty values stem from the fact that there is no possibility to reenter financial markets after default, hence the output loss is permanent.
} 
such a way that exit could happen in bad times. This parametrization should reflect well the situation governing the EMU. We assume that there are two possible exit-cost realizations, denoted with $C^{H}$ and $C^{L}$, both occurring with equal likelihood, and set $C^{H}=3.8$ and $C^{L}=0.8$.

In order to provide an interpretation for the utility loss associated with the union-exit, we perform a welfare analysis. At first we specify a counterfactual regime, comparable to our AUTARKY regime in the sense that the economy cannot lend or borrow internationally, and that it has a flexible exchange rate in such a way that there are no nominal frictions. However, a key distinction from the AUTARKY is that there is no output loss. We then compute the welfare of this economy in a stationary equilibrium and quantify permanent contractions in consumption - and associated loss in utility from consumption - that would be in (net present value) equivalent to the utility loss from exiting the union. ${ }^{22}$ The quantitative results reveal that our benchmark low-cost exit disutility scenario of $C^{L}=0.8$ is equivalent to a utility loss associated $9.4 \%$ permanent contraction in consumption, while the high-cost exit scenario of $C^{H}=3.8$ is equivalent to a $33 \%$ permanent contraction in consumption. These values may appear large, but they are not unrealistically high when compared to the tremendous output losses and unemployment spikes experienced in some of the eurozone countries during the recent crisis years. Moreover, these measured welfare losses need to be interpreted as gross (and not net) cost of the union-exit: an actual exit corrects the exchange rate misalignment, relieves the binding wage rigidity constraint and also lowers the real external debt burden through a partial default. All these feedbacks would generate income gains, which we do not take into account when quantifying the consumption-loss-equivalent of exit-costs. ${ }^{23}$

We solve the model by value function iteration and approximate the equilibrium using a discrete state space by assuming 31 grid points for tradable output, 101 grid points for debt and 151 grid points for nominal wage.

\subsection{Equilibrium Dynamics without Exit Rumors}

We first analyze the equilibrium dynamics of a baseline economy, where exit rumors are fully absent. To be precise, we specify that there were no previous exits, there are no exit rumors and the probability of exit rumors and any exit-realization emerging in the future equal zero.

\footnotetext{
${ }^{22}$ We measure the welfare by the value of the value function for the steady state level of tradable output, which is the only state variable for this problem.

${ }^{23}$ It is also important to highlight that exit cost does not need to be equal to the benefit of joining the union. Most likely, the loss of the benefits of being part of the union is only part of the exit cost, whereas important exit-cost items might be associated with the disruptive processes triggered by exiting the union.
} 
In terms of the model specification this is equivalent to the state of the monetary union of $\mathcal{M}_{t}=(u, n)$, i.e. no past exits $\left(h_{t}=u\right)$ in combination with no rumors about a potential exit $\left(e_{t}=n\right)$ and no exit-rumors possibility in the future $\left(\tilde{p}_{n}=0\right)$.

Shutting down the shocks stemming from the state of the monetary union allows to focus on the dynamics of the SOE in isolation of monetary union dynamics and provides with a baseline to compare our framework with the existing literature on sovereign default. The properties we will establish in this section will also serve as a reference point for the full-fledged quantitative framework where the SOE will be shocked with monetary-union exit-rumors of another member state.

We run 1000 simulations, each covering 5000 quarters. In every simulation, as initial conditions the SOE starts with zero net foreign assets, a low enough nominal wage - such that the nominal rigidity is not binding initially - and an average level of tradable output. Furthermore, the SOE is a member of the monetary-union and has not defaulted on its external debt in the past. This means that the SOE starts out in the UNION regime. In our numerical exercises that we report in Tables 2 and 3, we explore the likelihood of the SOE switching from the UNION regime into the regimes of EXIT (exiting the union, but honoring debt obligations), DEFAULT (defaulting on external debt, but remaining in the union) and AUTARKY (both defaulting and exiting) over the 5000-quarter time horizon in 1000 baseline simulations.

Table 2: Expected exit costs and the frequency of regime switches as a fraction (\%) of 1000-simulation series

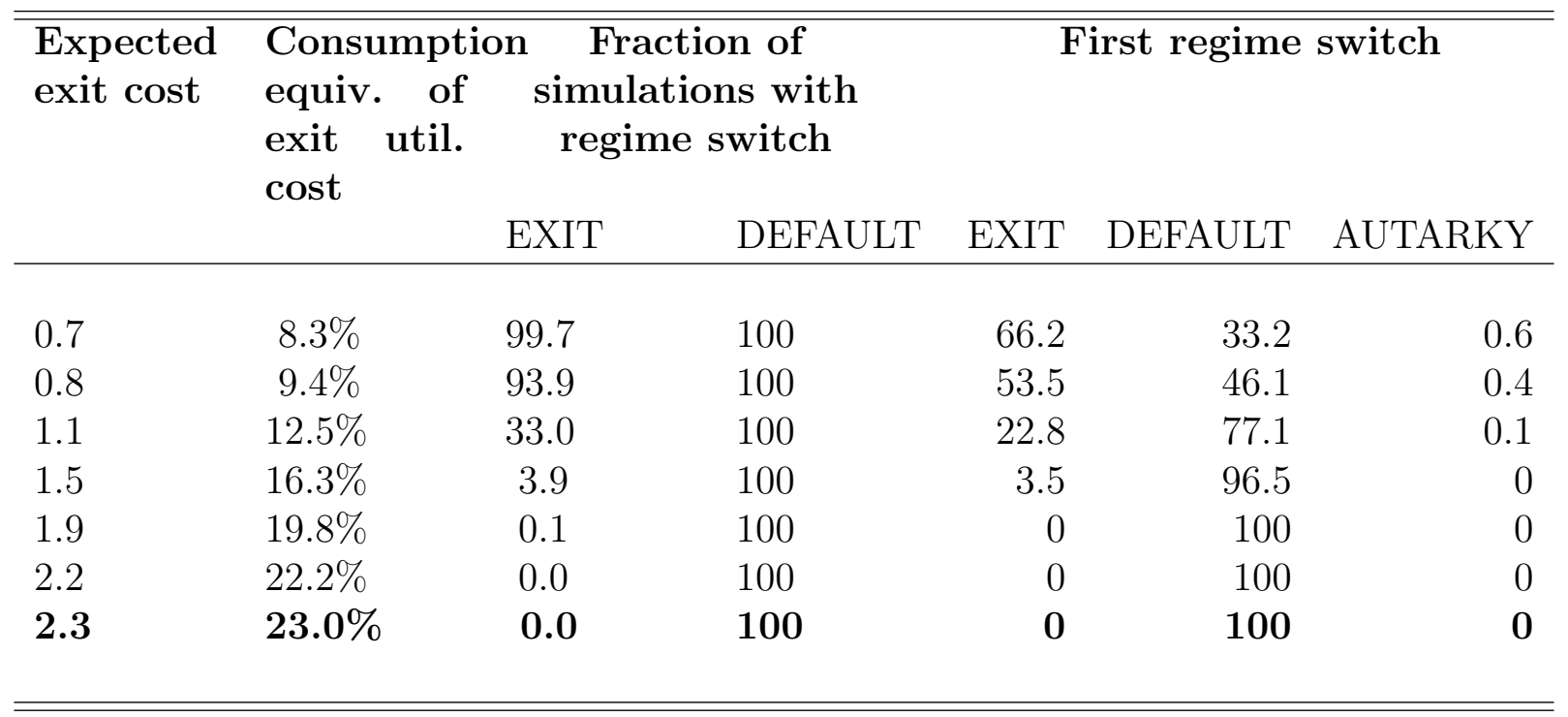


Table 2 reports the incidence of regime switches in our simulations. The first column presents the level of the expected cost of exiting the union, where we present the case of our benchmark $C^{e}$ expected utility cost parametrization in the last row. The second column provides the permanent consumption-loss equivalent of the expected exit cost. As reported in column 3 of Table 2, on the one hand, over the horizon of 5000 quarters (1250 years) the SOE executes "a default" in 100\% of the 1000-simulation series, independent of the expected cost of exiting the union. On the other hand, the fraction of simulation series, in which "an exit" occurs over the 1250-year time-horizon, crucially depends on the expected exit cost: an exit occurs in $99.7 \%$ of 1000 simulations under the lowest value of the expected exit-cost $\left(C^{e}=0.7\right)$ while no exits can be observed for high enough values of expected cost of exiting, to be precise for any $C^{e} \geq 2.2$. These results reveal that the model exhibits a high degree of non-linearity, where relatively small changes in the expected exit-cost can lead to large changes in the likelihood of executing a monetary union exit.

Another interesting dimension to investigate is the sequence of regime switches, i.e. an analysis of whether a default or an exit occurs first in the SOE which starts out in the UNION regime. We explore this in the last three columns of Table 2. The last column of Table 2 reveals that it is very rare that exit and default happen simultaneously in the same time period, implying a low probability of switching directly to AUTARKY. The impact of the cost of exit on the ordering of switches is as expected: the lower the exit cost the more likely it becomes for the SOE to exit the union first before defaulting on its external debt. The non-linearity of the model is also very well visible in the sequence of regime switches: a moderate change in the exit cost may lead to a substantial change in the likelihood of observing an exit first before default. ${ }^{24}$

Within our model, whenever an exit happens it is followed by a devaluation. The average devaluation accompanying a switch from the UNION to the EXIT regime ranges from $50.4 \%$ (the case of $C=0.7$ ) to $62.5 \%$ (the case of $C=1.5$ ). The average devaluation increases with the exit cost. This is an endogenous feature of the model, as with a higher exit cost the welfare loss from the nominal friction has to be larger for the country to pursue an exit. Hence, with a higher exit cost there are less exits but they happen under worse economic conditions, implying also a larger devaluation. Given the re-denomination of sovereign debt by the time of an exit, the size of the devaluation also represents the losses suffered by external lenders.

Importantly, using the baseline quantitative framework we can also study the comple-

\footnotetext{
${ }^{24}$ Such as what we observe between the second and the third rows of Table 3.
} 
Table 3: Expected exit costs and unconditional and conditional regime switch probabilities in baseline simulations (quarterly probabilities expressed in \%).

\begin{tabular}{|c|c|c|c|c|c|c|c|c|}
\hline \multirow[t]{2}{*}{$\begin{array}{l}\text { Expected } \\
\text { exit cost }\end{array}$} & \multirow{2}{*}{$\begin{array}{c}\text { Unconditional } \\
\text { probability } \\
\text { of exit } \\
\text { (full sample) }\end{array}$} & \multicolumn{3}{|c|}{$\begin{array}{c}\text { Probability of exit } \\
\text { after default } \\
\text { (in the first) }\end{array}$} & \multirow{2}{*}{$\begin{array}{c}\text { Unconditional } \\
\text { probability } \\
\text { of default } \\
\text { (full sample) }\end{array}$} & \multicolumn{3}{|c|}{$\begin{array}{c}\text { Probability of default } \\
\text { after exit } \\
\text { (in the first) }\end{array}$} \\
\hline & & $1 \mathrm{y}$ & $2 y$ & $5 y$ & & $1 y$ & $2 y$ & $5 y$ \\
\hline 0.7 & 0.20 & 1.13 & 0.83 & 0.44 & 0.32 & 1.06 & 0.79 & 0.48 \\
\hline 0.8 & 0.08 & 0.70 & 0.46 & 0.30 & 0.30 & 1.07 & 0.77 & 0.49 \\
\hline 1.1 & 0.01 & 0.42 & 0.28 & 0.13 & 0.27 & 0.88 & 0.60 & 0.55 \\
\hline 1.5 & 0.00 & 0.05 & 0.03 & 0.02 & 0.24 & 0.71 & 0.36 & 0.29 \\
\hline 1.9 & 0.00 & 0.03 & 0.01 & 0.01 & 0.24 & 0.00 & 0.00 & 0.00 \\
\hline 2.2 & 0 & 0 & 0 & 0 & 0.38 & NA & NA & NA \\
\hline 2.3 & 0 & 0 & 0 & 0 & 0.38 & NA & NA & NA \\
\hline
\end{tabular}

* "0" refers to prob. $=0$, "0.00" refers to $0<$ prob. $<0.01$, and "NA" refers to conditional probabilities that could not have been calculated as the condition event did not occur in baseline simulations.

mentarity between exit and default. The numerical analysis of Table 3 reveals that default increases the probability of a subsequent exit from the monetary union: for instance, when focusing on the lowest expected cost of exit, the probability of the monetary-union exit within a year after a default is more than five times higher than the unconditional probability of a monetary-union exit. This complementarity becomes stronger as the expected cost of union-exit increases (up until the point where no exits occur).

The mechanism behind this complementarity works through the output loss of default: after a default incident the SOE suffers an output loss and cannot smooth its consumption because of the exclusion from financial markets. Therefore, following default the optimal wage in the economy falls, increasing the likelihood of the nominal wage constraint to bind and lowering international competitiveness borne by the fixed exchange rate. Since the output loss is persistent, the nominal rigidity may generate persistent unemployment. ${ }^{25}$

The reverse causality - although likely - is quantitatively less strong: Depending on the expected cost of exit, a monetary-union exit increases the subsequent probability of default within a year by three to four times. The quantitative effect of an exit on default is smaller than that of default on exit because exiting the union already features a partial default, reducing the need for an outright default on external lenders.

\footnotetext{
${ }^{25}$ This resembles the optimality of devaluation following the incidence of default in Na et al. (2018).
} 


\subsection{Equilibrium Dynamics with Exit Rumors}

In the previous subsection, we explored the baseline equilibrium dynamics in which exitrumors are absent and given the unknown cost of union-exit the SOE never executes a monetary union departure as long as $C^{e}$ is high enough. We are now ready to explore the consequences of exit-rumors. For this analysis at first we set $C^{H}=3.8$ and $C^{L}=0.8$ (with $C^{e}=2.3$ ) as a benchmark such that in the absence of exit rumors the country would never execute a monetary union exit by itself for any given $\mathcal{S}_{t}$ that we concentrate on. In our quantitative analysis that we present in Table 4 we also study several alternative exitcost specifications. As a benchmark we set a high enough value for $C^{e}$, because until the emergence of Grexit rumors no country had ever considered to leave the European Economic and Monetary Union. Moreover, exit-risks were never priced in the market for European sovereign bonds, as sovereign bond prices of peripheral EMU countries equaled to the riskfree rates charged on German bonds until 2009.

We surprise the SOE characterized by the baseline simulation dynamics (with $C^{e}=$ 2.3 with an exit-rumors in order to explore the dynamic implications of an unexpected exit-rumors shock. Specifically, we let the state of exit-rumors in the monetary union $\left(e_{t}\right)$ unexpectedly change from $n$ to $s$. This means that after the rumors shock is realized, there will be another member state potentially exiting the union before the next period begins. From this point on we will continue to refer to the country whose macroeconomic behavior we are studying as the SOE, and the member-state that is the subject of exit rumors as country-X. ${ }^{26}$

For tractability purposes, we assume that the "perceived" ex-ante probability that country-X actually exits the union $(p)$ equals 1 , whereas ex-post an exit does not materialize. This property requires some level of myopia for the agents of the model. This assumption substantially simplifies computations, but is of no qualitative importance. ${ }^{27}$

The arrival of exit-rumors stemming from country-X does not have a direct consequence for the SOE, as it does not change its aggregate state $\mathcal{S}_{t}$. However, rumors shock has substantial indirect effects through the possibility of exit-cost information revelation before the next period actions are taken, which will have dynamic implications for the SOE and in particular for its current bond prices.

\footnotetext{
${ }^{26}$ In the case of the European crisis, one can think of Greece as country-X and any of the peripheral countries affected by contagion, e.g. Portugal, as the SOE.

${ }^{27}$ Quantitatively the myopia assumption increases the contagion effect. However, given the large contagion effects that we find through the rumors shock, it might be the case that modeling the rumors shock without myopia could bring our results closer to reality.
} 
Table 4: Default Implications of Exit Rumors

\begin{tabular}{|c|c|c|c|c|c|c|}
\hline \multicolumn{3}{|c|}{ "Experiment setup } & \multirow[t]{2}{*}{ Exit Prob. (\%) } & \multicolumn{3}{|c|}{$\begin{array}{l}\text { Additional defaults generated by Exit-Rumors } \\
\text { as \% of no-default periods in baseline sim. }\end{array}$} \\
\hline$C^{e}$ & $C^{L}$ & $C^{H}$ & & all periods & $\begin{array}{l}\text { periods with } \\
\quad d_{t}>0\end{array}$ & $\begin{array}{c}\text { periods with } \\
d_{t}>0, w_{t-1}>\bar{w} \\
\& y_{t}^{T}<y^{T}=1\end{array}$ \\
\hline 2.3 & 0.8 & 3.8 & 0 & 0.78 & 1.44 & 4.43 \\
\hline 2.3 & 0.7 & 3.9 & 0 & 1.20 & 2.21 & 6.20 \\
\hline 2.3 & 1.1 & 3.5 & 0 & 0.42 & 0.78 & 1.92 \\
\hline 2.3 & 1.9 & 2.7 & 0 & 0.25 & 0.46 & 0.38 \\
\hline 1.5 & 0.7 & 2.3 & 0.00 & 0.75 & 1.38 & 5.06 \\
\hline 1.5 & 0.8 & 2.2 & 0.00 & 0.43 & 0.79 & 4.08 \\
\hline 1.5 & 1.1 & 1.9 & 0.00 & 0.16 & 0.30 & 1.52 \\
\hline
\end{tabular}

* $\bar{w}$ is the median equilibrium nominal wage that reveals in baseline simulations.

How exactly does the mechanism of the model work? Without exit rumors, it is impossible for the exit cost to be revealed (exogenously) in the next period; therefore, both the SOE and international investors know that the SOE's government will undertake its decisions based on the expected exit cost, $C^{e}=2.3$. This implies that the exit likelihood of the SOE equals zero and the exit-driven partial-default risk does not need to be priced in when extending funds to the SOE's government in international financial markets.

If there is a positive chance that the cost of exit is going to be revealed before the nextperiod decisions are taken by the SOE, the pricing of bonds gets revised. The reason for this adjustment - as we delineated before - is that in that case the next-period decisions are going to be determined based on one of the two possible cost realizations, either with $C^{L}=0.8$ or with $C^{H}=3.8$. If the realized cost figure will turn out to be $C^{H}$, the SOE's monetary union exit likelihood will not exhibit any change from that of the baseline. The reason for this invariance is that for any $\mathcal{S}_{t}$, the $\mathrm{SOE}$ was not going to execute a union-exit given the expected utility cost of $C^{e}=2.3$, as we analyzed in the baseline equilibrium dynamics. Hence, by taking a realized cost figure of $C^{H}$ that is higher than $C^{e}=2.3$ as given, it will not find a monetary-union departure optimal either. However, if the realized cost figure will be $C^{L}$ (with $C^{L}<C^{e}=2.3$ ), the SOE might find it optimal to leave the union for some $\mathcal{S}_{t}$ - as long as $C^{L}$ is low enough. 
Table 5: Default Multipliers

\begin{tabular}{|c|c|c|c|c|c|}
\hline \multicolumn{3}{|c|}{ Experiment setup } & \multicolumn{3}{|c|}{$\frac{\text { Default Probability with Exit Rumors }}{\text { Default Probability without Exit Rumors }}$} \\
\hline$C^{e}$ & $C^{L}$ & $C^{H}$ & all periods & $\begin{array}{c}\text { periods with } \\
d_{t}>0\end{array}$ & $\begin{array}{c}\text { periods with } \\
d_{t}>0, w_{t-1}>\bar{w} \\
\& y_{t}^{T}<y^{T}=1\end{array}$ \\
\hline 2.3 & 0.8 & 3.8 & $\frac{0.78+0.38}{0.38}=\mathbf{3 0 5 \%}$ & $\frac{1.44+0.70}{0.70}=\mathbf{3 0 5 \%}$ & $\frac{4.43+1.00}{1.00}=\mathbf{5 4 3 \%}$ \\
\hline 2.3 & 0.7 & 3.9 & $\frac{1.20+0.38}{0.38}=415 \%$ & $\frac{2.21+0.70}{0.70}=415 \%$ & $\frac{6.20+1.00}{1.00}=720 \%$ \\
\hline 2.3 & 1.1 & 3.5 & $\frac{0.42+0.38}{0.38}=210 \%$ & $\frac{0.78+0.70}{0.70}=211 \%$ & $\frac{1.92+1.00}{1.00}=292 \%$ \\
\hline 2.3 & 1.9 & 2.7 & $\frac{0.25+0.38}{0.38}=166 \%$ & $\frac{0.46+0.70}{0.70}=166 \%$ & $\frac{0.38+1.00}{1.00}=138 \%$ \\
\hline
\end{tabular}

${ }^{*} \bar{w}$ is the median equilibrium nominal wage that reveals in baseline simulations. The denominators in fractions are the default probabilities without exit rumors.

Since the primary reason to incur an exit utility-loss is to correct the exchange rate misalignment of the country, a future exit from the monetary union will come along with the introduction of a new currency and an immediate re-denomination of the stock of outstanding debt into this new currency, making a devaluation equivalent to a partial default. Therefore, when exit-rumors are present, expected losses on international lenders that would materialize in the next period after a potential $C^{L}$ revelation are taken into account when pricing the SOE-bonds in the current period.

Our mechanism thus yields that even in the absence of a shock to the aggregate state of the SOE $\left(\mathcal{S}_{t}\right)$, the bond prices of the SOE should go down. Low bond prices, or in other words high interest rates, in turn could induce an outright default to be optimal for the SOE's government, even if the government does not choose to execute a monetary-union exit in any time-period soon before or soon after the default. We interpret defaults triggered by exit-rumors shocks - in the absence of additional shocks to fundamentals and any realized exit from the union - as contagion within the monetary union. Since the fall in bond prices is the result of a potential future union-exit under a low exit-cost realization, the contraction in bond prices gets magnified by the benefits of a potential exit. Therefore, the contagion is more likely to occur and to be more pronounced in countries that have high debt levels and/or experience a binding nominal wage rigidity constraint. Next we turn to analyzing 
these channels quantitatively.
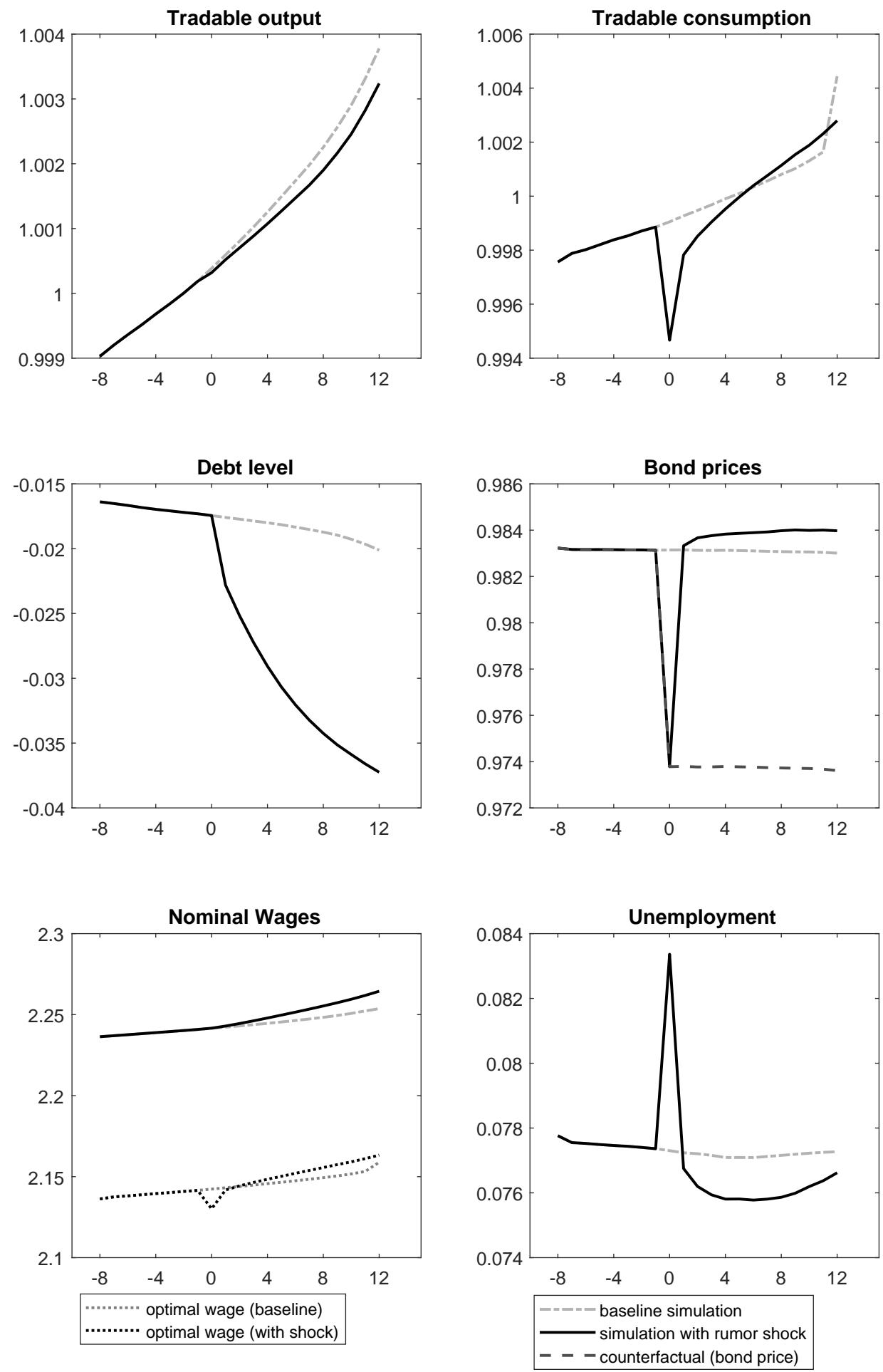

Figure 3: Simulation results - baseline simulation vs simulation with a rumors shock. 
First, Tables 4 and 5 analyze the implications of exit-rumors on the SOE's default likelihood, in which we delineate on the number of new default incidences that will emerge after the exit-rumors shock. Specifically, in Table 4 we present the fraction of periods (as a percentage) of the baseline simulation periods, where the exit-rumors shock pushes the SOE to default, although no default was going to be observed in the absence of exit-rumors. As we illustrate in the top row of Table 4 , given our benchmark parametrization with $C^{H}=3.8$ and $C^{L}=0.8$ (and $C^{e}=2.3$ ), the exit-rumors shock generates new sovereign default incidences in $0.78 \%$ of all simulation periods where default wasn't going to be observed without the exit-rumors. Since default occurred (unconditionally) in $0.38 \%$ of all periods (quarters) in the baseline ${ }^{28}$, which continue to occur with exit rumors, as we report in Table 5 , the unconditional probability of sovereign default with exit-rumors is $305 \%$ that of the baseline simulations without exit-rumors.

Furthermore, the exit-rumors shock increases the likelihood of default substantially more if the SOE is indebted, has lower than average output realizations and a binding wage constraint. Specifically, following an exit-rumors shock, new default incidences get reported in $1.44 \%$ of baseline simulation periods with positive debt. In periods when the SOE is indebted and also exhibits high wages coupled with lower than average tradable output inducing the wage constraint to bind - we record new default incidences in $4.43 \%$ of the relevant range of periods. As we present in Table 5, these new default incidences imply that the probability of default with exit-rumors is $543 \%$ that of the baseline without exit-rumors, when one focuses on times of indebtedness coupled with a recession. Therefore, the exitrumors mechanism in hand generates quantitatively important contagion effects for healthy members of a monetary union and disproportionately more so for those that are indebted and going through a recession, such as some of the countries in peripheral EMU right before the emergence of Grexit rumors.

Quantitative experiments in the second row of Table 4 indicate that keeping the expected exit-cost at $C^{e}=2.3$ and varying the degree of the spread between $C^{H}$ and $C^{L}$ (exit-cost uncertainty) does not alter the qualitative properties obtained in the top row of Table 4. Quantitatively the default implications of exit-rumors get substantially stronger if we were to increase the difference $\left(C^{H}-C^{L}\right)$ from 3.0 to 3.2 , as we document in Table 5. Similarly, as we present in the third row of Table 4, lowering the expected-cost of exit from 2.3 to 1.5 does not alter the key qualitative properties either, while retaining strong quantitative

\footnotetext{
${ }^{28}$ The quarterly unconditional default probability of $0.38 \%$ is equivalent to an unconditional annual probability of $1.51 \%$.
} 

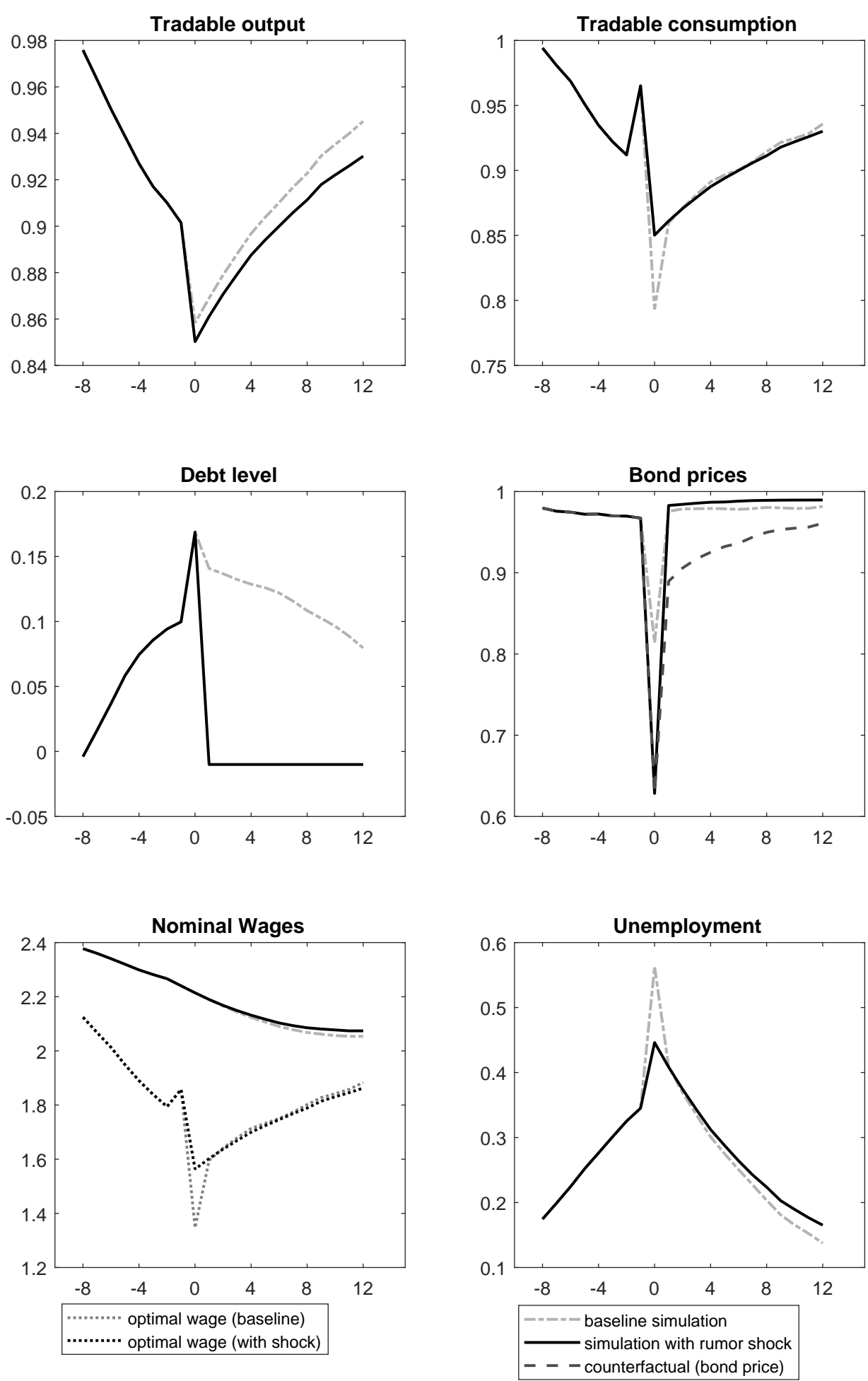

Figure 4: Simulation series in which there is no default in the baseline, but default happens after the rumors shock. 
implications.

Although with exit-rumors the SOE defaults more often than the baseline of "no-exitrumors", as indicated in Table 4 the government continues to remain in the monetary-union also with exit-rumors. This resembles the situation of peripheral EMU countries during the eurozone debt crisis: following the Grexit rumors, countries such as Portugal and Cyprus experienced contractions in prices on sovereign bonds and soon after they applied for bail-out funds. During this period neither of these countries attempted to exit the EMU.

Figures 3 and 4 present the behavior of a set of macroeconomic variables - averaged across simulations - for the benchmark exit-cost specification with $C^{H}=3.8$ and $C^{L}=0.8$. Throughout the panels of both figures, the dashed-dotted gray lines represent the "average equilibrium values" across the 1000-baseline simulations without exit-rumors. In comparison, the solid black lines display the averages over simulation series, in which an exit-rumors hits the SOE in period zero.

The upper left panel of Figure 3 shows the dynamics of the tradable output, which exhibits a rising trend over the period that we concentrate on. However, looking at the scale reveals that the tradable endowment is virtually constant, as the change of its value over the period of 5 years is approximately one-tenth of the standard deviation. ${ }^{29}$

The effect of the exit-rumors shock becomes the most visible in the middle-right panel of Figure 3, where we study the dynamics of the SOE-bond prices: following the exit-rumors shock, the average price of SOE-bonds across all simulations falls. This reflects the perceived risk that an actual exit could happen in the near future for the SOE after exit-rumors, as a result of which its external debt could get re-denominated. The low bond prices, in turn, force the SOE to lower its debt level as it can be observed in the middle-left panel of Figure 3. The contraction in SOE's indebtedness causes the consumption of tradable output to contract around the time of the exit rumors, which is depicted in the upper-right panel. The feedback through the adjustment in the level of indebtedness allows the SOE-bond prices to rebound a period after the exit-rumors shock hits the economy, even though the shock persists further. Finally, the dashed black line in the middle-right panel of Figure 3 displays the counterfactual bond price that would have prevailed after exit-rumors, if the SOE's government were not to adjust the country's external debt. In that case, as expected, the price on sovereign bonds remains low for a longer time-period, as it was experienced in

\footnotetext{
${ }^{29}$ The slightly upward trend in tradable output might result from the way we choose the sample, as we drop thirteen periods prior to the default-event in the baseline simulation and defaults happen mostly when output falls. If anything, this bias will underestimate the contagion effect that we are capturing. More details on sampling for the simulations is provided in Appendix A.
} 
peripheral EMU countries during the eurozone crisis.

A key feature of our model is the rigidity in nominal wages that would be dictated by a binding wage constraint. We can note in the lower left panel of Figure 3 that optimal wages in both baseline simulations (without rumors shocks) and in simulations with exitrumors are lower than the realized wages in equilibrium, implying that the nominal wage constraint is binding in simulation-periods we are exhibiting. The contraction in tradable consumption following the exit-rumors impacts the non-tradable sector as well through its effect on nominal wages: the contraction in tradable consumption suppresses the price of nontradables and as a result the optimal nominal wage level. Lower optimal wage rate induces the wage rigidity constraint to bind even more - translating into higher unemployment rates in the non-tradable sector as depicted in the lower-right panel of Figure 3.

In $0.78 \%$ of the simulation series the rumors shock triggers a default, where there would have been no default if exit rumors were not present, as we covered in the baseline simulations of Section 4.2. In these simulations default happens in the first period the rumors shock hits the economy. We interpret the additional default incidences generated by the exit-rumors as contagion. To delineate more on this contagion effect, Figure 4 presents the behavior of the macroeconomic variables averaged across those simulations in which there is a default in the first period the rumors shock hits, although no default is observed in the baseline simulations without exit-rumors. In this respect, this analysis concentrates on the simulations of the SOE, in which the SOE was under stress but healthy enough not to default in the absence of exit rumors. The SOE gets pushed to default after the arrival of exit-rumors. Therefore, in these special-case simulations the SOE's tradable output features a declining trend while its debt is rising before the exit-rumors hits, as presented in the upper-left and middle-left panels of Figure 4.

The simulation results that we observe in Figure 4 are qualitatively consistent with our findings in Table 4 such that the rumors shock is more likely to trigger a default if the economy is highly indebted, experiencing a recession and/or unemployment is high due to a binding nominal wage rigidity constraint.

Figure 4 shows that bond prices fall substantially after the exit-rumors hits the economy. We would like to note though that the bond prices would have been contracting for these sub-sample simulations even without rumors shock - as observed in the middle-right panel of Figure 4, and default possibility would have been priced, although no default was going to be realized ex-post. Due to the relatively high indebtedness of the SOE in these sub-sample simulations (with or without exit-rumors), the government does not find it optimal to reduce 
the country's debt level and instead it increases indebtedness further before the arrival of exitrumors, causing a spike in the tradable consumption. When exit-rumors arrive and contract the bond prices further, it pushes the government of the SOE to default on its external debt. This channel increases the consumption of tradable output in the short run - relative to the baseline simulations without exit-rumors, because with the help of default the government avoids debt repayment to international investors. This standard property of Eaton-Gersovitz style models is qualitatively different than what we observed in the full-sample simulations of Figure 3. The elevation in tradable-consumption in the short-run is the main motive for the SOE's government to default, since defaulting allows the government to withhold its debt repayment. The relatively small contraction in tradable-consumption - compared to the full-sample simulations - also implies that the optimal price of non-tradables and the optimal wage rate fall less compared to the baseline, reducing short-term unemployment consequences of exit-rumors.

The costs of an outright default for the SOE are twofold: the output loss penalty and the exclusion from international financial markets. These two cost items reduce the consumption of tradable-output and keep it at those low levels in the periods following the incidence of default. This is also why the defaulting SOE experiences high levels of unemployment for several periods compared to the full sample simulations.

\subsection{Uncertain Exit Costs and Cost of Borrowing}

Exit-rumors shock deteriorates macroeconomic conditions of the SOE and potentially pushes the country's government to default to the extent it raises the cost of borrowing. In order to deepen our understanding concerning the effects of exit rumors on sovereign borrowing costs, in this section we vary the degree of uncertainty governing the union-exit cost and analyze the consequences of this variation on deviations in interest rates from the baseline interest rates by the time the exit-rumors shock hits the economy. We measure the potential "contagion effect" of exit-rumors by comparing the interest rate hikes caused by the exitrumors - averaged across simulations - for different degrees of exit-cost uncertainty.

Figure 5 presents this analysis for the benchmark expected cost of exit, $C^{e}=2.3$, by varying the degree of uncertainty across a spectrum of cost specifications and recording the deviations in average interest rates (from their baseline averages) following the exit-rumors shock. In our analysis we explore across a wide range of uncertainty specifications, starting from A1, with $C^{L}=0.7$ and $C^{H}=3.9$, up to A7, with $C^{L}=2.2$ and $C^{H}=2.4$.

We would like to note that the A7-specification is an extreme case (where uncertainty is 


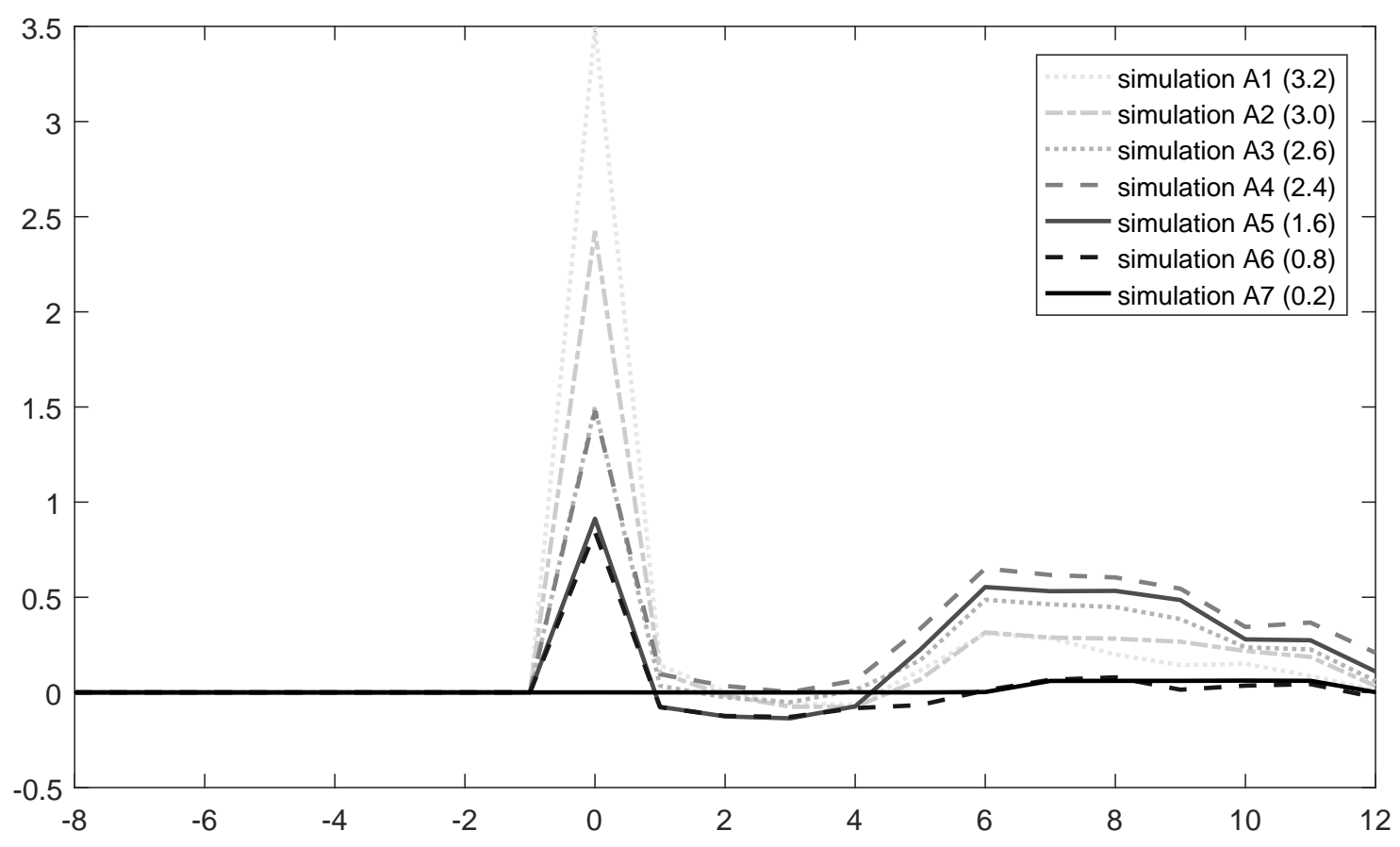

Figure 5: Contagion effect (rumors shock) on interest rates (in percentage points) for different exit cost parametrizations. $C^{e}=2.3$ is constant across different parametrizations, $C^{H}-C^{L}$ reported in parentheses.

practically absent) which does not yield much of a fluctuation in interest rates during times of exit-rumors. This quantitative property holds, because for both $C^{L}=2.2$ and $C^{H}=2.4$ the SOE does not exit the monetary-union for any aggregate state of the country. For the remaining uncertainty specifications, at the onset of the exit-rumors quantitatively visible deviations in interest rates get recorded. Furthermore, these short-run effects are larger the larger is the difference between $C^{H}$ and $C^{L}$. The medium-run effect of exit-rumors on interest rates is not monotonic in exit-cost uncertainty, because the direct effect of the rumors-shock brings along an adjustment in external borrowing, reducing the default and exit risks.

We repeat the same analysis also for a range of uncertainty-specifications for $C^{e}=1.5$ and present the quantitative results in Figure 6. Similar qualitative and quantitative effects of exit-cost uncertainty on interest rates are observed for this alternative expected cost specification as well.

The results from this section have clear policy implications, as it shows that exit-cost uncertainty increases the fragility of the economies in a monetary union, implying that policy makers should aim for exit-cost transparency in order to eliminate financial instability and contagion in a currency-area. 


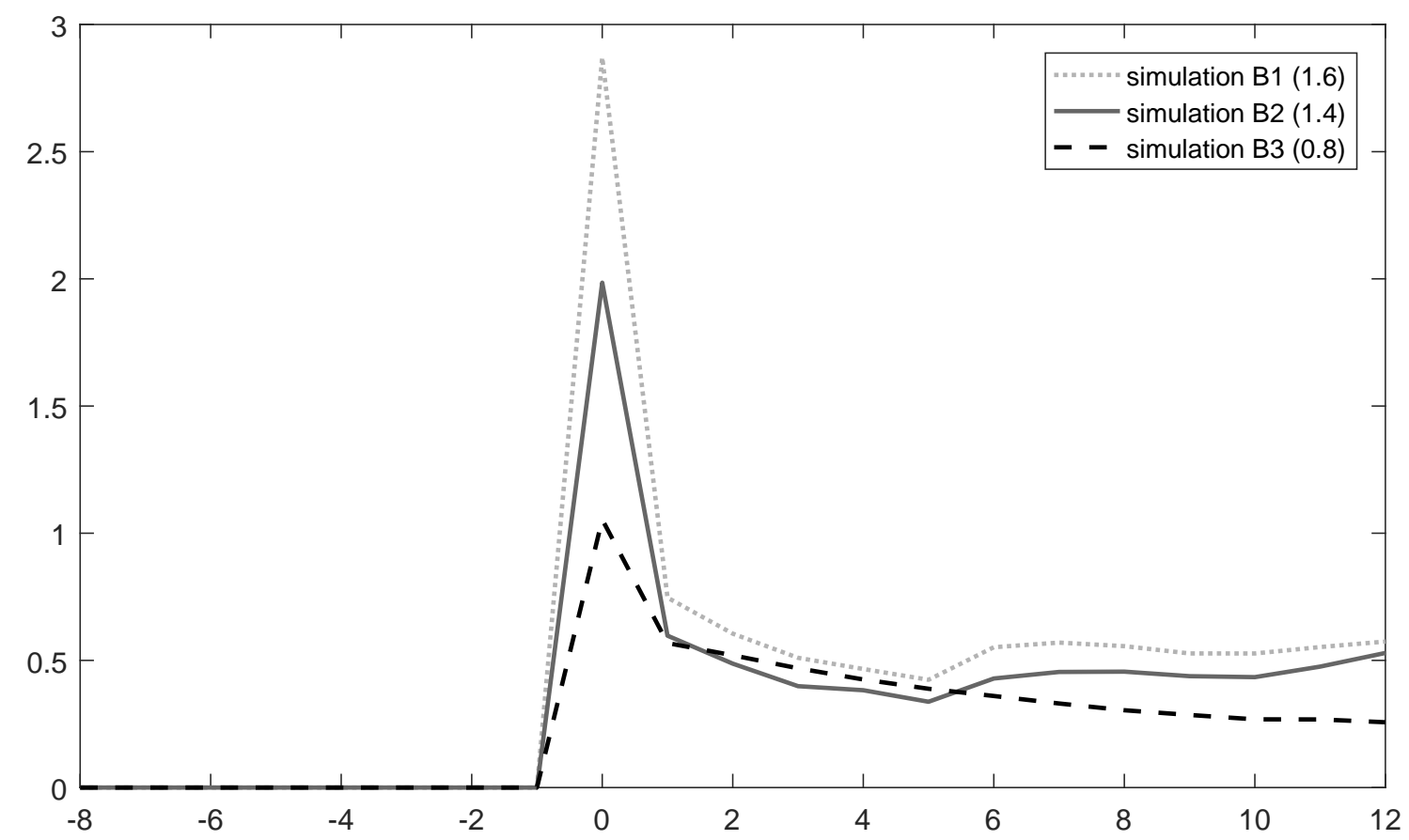

Figure 6: Contagion effect (rumors shock) on interest rates (in percentage points) for different exit cost parametrizations. $C^{e}=1.5$ is constant across different parametrizations, $C^{H}-C^{L}$ reported in parentheses.

\section{Conclusion}

We studied the interactions between default and monetary-union exit decisions of a small open economy. Our small open economy model features nominal wage rigidities, which induce exchange-rate misalignments to be painful for the macroeconomy as in Na et al. (2018) and Schmitt-Grohé and Uribe (2016). Within this setup we analyze an Eaton and Gersovitz (1981) type endogenous default of the government on the country's external debt and importantly we endow the government of the small open economy also with an endogenous monetary-union exit decision. As key aspects of the set-up we specify that the union-exit is costly, and moreover the cost of exit is uncertain and becomes known to the members of the monetary-union only when a member state executes an actual departure from the union.

Using this model we uncover a novel contagion mechanism that could trigger a sovereign debt crisis (and default) in a country with healthy enough ex-ante fundamentals after the emergence of union-exit rumors associated with another member state despite the absence of any realization of a monetary-union exit. The mechanism in hand implies that the potential of a low exit-cost realization in the near future - such as a successful and not-so-painful Grexit 
process - is likely to generate a domino-effect and cause subsequent exits. Since a union-exit of the country of our interest in the future will also imply a partial default, external lenders take such short-run expectations into account around the times of an exit-rumors and raise interest rates, even for a not-so-unhealthy member state.

We calibrate the theoretical framework and present quantitative exercises that illustrate that the mechanism can replicate the qualitative properties of the sovereign debt crisis observed in EMU over the last decade. Moreover, the model accounts for rising interest rates in peripheral EMU countries - after the Grexit rumors - as well as high unemployment rates and economic slowdown in these countries during the eurozone debt crisis. Most importantly, we quantify that an exit-rumors shock would triple an average country's default likelihood, while it raises the default likelihood for a country which was already in a recessionary-trend to five times of its baseline-level. Therefore, our framework provides a novel and quantitatively important angle to evaluate the eurozone debt-crisis.

The contagion mechanism we describe is not the only possible source of contagion within the EMU. Other potential contagion channels include common lenders, wake-up call contagion resulting from the revision of Greek fiscal data in 2009-10, or the correlation of shocks across the union. What distinguishes the contagion channel that we present in this paper from the rest is that it corresponds well with the events observed during the eurozone crisis. In particular, contagion was limited only to the countries of the monetary union and the correlation of risk premia that emerged at the onset of the crisis persisted over time, with interest rates of the affected countries reacting to news about other eurozone countries. The former characteristic weakens the case for common lenders as the sole channel of contagion, whereas the latter characteristic makes the case for wake-up call contagion less likely.

Bail-outs could be another promising channel that could explain contagion within a monetary union. We perceive bailouts in a monetary union to be complementary to the channel presented in this paper, which potentially could reinforce the effects that we uncovered.

Our framework can be extended in a number of interesting dimensions. Among them, one policy relevant case would be the study of interactions between exit rumors emerging from different countries. In the theoretical and the quantitative analysis of the current paper we concentrated on the implications of exit rumors stemming from one member state to the macroeconomic dynamics and financial instability of another one. It could be interesting to analyze the feedback loops between exit-rumors of different countries, which can reinforce the likelihood of short-run exit-cost revelation and financial contagion in the monetary union. Another interesting dimension to consider could be the incorporation of a central policy 
maker at the union-level and the analysis of its optimal reactions to contagion resulting from exit rumors. These interesting extensions go beyond the purpose of the current paper and therefore we leave them to future research. 


\section{References}

Aguiar, M. and Amador, M. (2014). Sovereign debt. In Handbook of International Economics Vol. 4, pages 647-87. North-Holland.

Aguiar, M., Amador, M., Farhi, E., and Gopinath, G. (2015). Coordination and Crisis in Monetary Unions. Quarterly Journal of Economics, XXXIII(2):1727-1779.

Aguiar, M. and Gopinath, G. (2006). Defaultable debt, interest rates and the current account. Journal of International Economics, 69(1):64-83.

Aizenman, J., Hutchison, M., and Jinjarak, Y. (2013). What is the risk of European sovereign debt defaults? Fiscal space, CDS spreads and market pricing of risk. Journal of International Money and Finance, 34:37-59.

Alvarez, F. and Dixit, A. (2014). A real options perspective on the future of the Euro. Journal of Monetary Economics, 61(C):78-109.

Ang, A. and Longstaff, F. A. (2013). Systemic sovereign credit risk: Lessons from the U.S. and Europe. Journal of Monetary Economics, 60(5):493-510.

Arellano, C. (2008). Default Risk and Income Fluctuations in Emerging Economies. American Economic Review, 98(3):690-712.

Arellano, C. and Ramanarayanan, A. (2012). Default and the Maturity Structure in Sovereign Bonds. Journal of Political Economy, 120(2):187-232.

Athanassiou, P. (2009). Withdrawal and expulsion from the EU and EMU. ECB Legal Working Paper Series 10, European Cental Bank.

Beetsma, R., Giuliodori, M., de Jong, F., and Widijanto, D. (2013). Spread the news: The impact of news on the European sovereign bond markets during the crisis. Journal of International Money and Finance, 34:83-101.

Beirne, J. and Fratzscher, M. (2013). The pricing of sovereign risk and contagion during the European sovereign debt crisis. Journal of International Money and Finance, 34:60-82.

Bernoth, K., Hagen, J. V., and Schuknecht, L. (2012). Sovereign risk premiums in the European government bond market. Journal of International Money and Finance, 31(5):975995. 
Bolton, P. and Jeanne, O. (2011). Sovereign Default Risk and Bank Fragility in Financially Integrated Economies. IMF Economic Review, 59(2):162-194.

Broner, F., Erce, A., Martin, A., and Ventura, J. (2014). Sovereign debt markets in turbulent times: Creditor discrimination and crowding-out effects. Journal of Monetary Economics, 61(C):114-142.

Brutti, F. and Sauré, P. (2015). Transmission of sovereign risk in the euro crisis. Journal of International Economics, (forthcomming).

Chatterjee, S. and Eyigungor, B. (2012). Maturity, Indebtedness, and Default Risk. American Economic Review, 102(6):2674-2699.

Constâncio, V. (2012). Contagion and the European debt crisis. Financial Stability Review, (16):109-121.

Corsetti, G. and Dedola, L. (2016). The mystery of the printing press: Monetary policy and self-fulfilling debt crises. Journal of the European Economic Association, 14(6):1329-1371.

Corsetti, G., Kuester, K., Meier, A., and Müller, G. J. (2014). Sovereign risk and beliefdriven fluctuations in the euro area. Journal of Monetary Economics, 61(C):53-73.

De Santis, R. A. (2014). The euro area sovereign debt crisis: Identifying flight-to-liquidity and the spillover mechanisms. Journal of Empirical Finance, 26:150 - 170.

De Santis, R. A. (2015). A measure of redenomination risk. ECB Working Paper Series 1785, European Cental Bank.

Durdu, C. B., Nunes, R., and Sapriza, H. (2013). News and sovereign default risk in small open economies. Journal of International Economics, 91(1):1 - 17.

Eaton, J. and Gersovitz, M. (1981). Debt with Potential Repudiation: Theoretical and Empirical Analysis. Review of Economic Studies, 48(2):289-309.

ECB (2012). Speech by mario draghi at the global investment conference in london, 26 july 2012.

Favero, C. A. (2013). Modelling and forecasting government bond spreads in the euro area: A GVAR model. Journal of Econometrics, 177:343-356. 
Ghosh, A. R., Ostry, J. D., and Qureshi, M. S. (2013). Fiscal space and sovereign risk pricing in a currency union. Journal of International Money and Finance, 34:131-163.

Kohonen, A. (2014). Transmission of government default risk in the eurozone. Journal of International Money and Finance, 47(C):71-85.

Kriwoluzky, A., Mueller, G., and Wolf, M. (2015). Exit expectations and debt crises in currency unions. CEPR Discussion Papers 10817, C.E.P.R. Discussion Papers.

Lizarazo, S. V. (2013). Default risk and risk averse international investors. Journal of International Economics, 89(2):317-330.

Ludwig, A. (2014). A unified approach to investigate pure and wake-up-call contagion: Evidence from the Eurozone's first financial crisis. Journal of International Money and Finance, 48(Part A):125-146.

Mendoza, E. G. and Yue, V. Z. (2012). A General Equilibrium Model of Sovereign Default and Business Cycles. The Quarterly Journal of Economics, 127(2):889-946.

Mink, M. and de Haan, J. (2013). Contagion during the Greek sovereign debt crisis. Journal of International Money and Finance, 34:102-113.

Na, S., Schmitt-Grohé, S., Uribe, M., and Yue, V. Z. (2018). The Twin Ds: Optimal Default and Devaluation. American Economic Review, (forthcomming).

Obstfeld, M. (1994). The Logic of Currency Crises. NBER Working Papers 4640, National Bureau of Economic Research, Inc.

Obstfeld, M. (1996). Models of currency crises with self-fulfilling features. European Economic Review, 40(3-5):1037-1047.

Obstfeld, M. (1997). Destabilizing effects of exchange-rate escape clauses. Journal of International Economics, 43(1):61 - 77.

Park, J. (2013). Contagion of sovereign default risk: the role of two financial frictions. MPRA Working Paper \#55197.

Schmitt-Grohé, S. and Uribe, M. (2016). Downward Nominal Wage Rigidity, Currency Pegs, and Involuntary Unemployment. Journal of Political Economy, 124(5):1466 - 1514. 
Schumacher, J., Chamon, M., and Trebesch, C. (2015). Foreign Law Bonds: Can They Reduce Sovereign Borrowing Costs? Annual Conference 2015 (Muenster): Economic Development - Theory and Policy 113199, Verein für Socialpolitik / German Economic Association.

Yue, V. Z. (2010). Sovereign default and debt renegotiation. Journal of International Economics, 80(2):176-187. 